\title{
Deposit insurance and reinsurance
}

\author{
Volker Britz ${ }^{1} \cdot$ Hans Gersbach ${ }^{2}$. Hans Haller ${ }^{3}$
}

Received: 17 February 2020 / Accepted: 23 April 2021 / Published online: 29 July 2021

(c) The Author(s) 2021

\begin{abstract}
We study the consequences and optimal design of bank deposit insurance and reinsurance in a general equilibrium setting. The model involves two production sectors, financed by bonds and bank loans, respectively. Financial intermediation by banks is required in the model as we assume that one of the production sectors is risky and requires monitoring by banks. Households fund banks through deposits and equity. Deposits are explicitly insured and banks pay a premium per unit of deposits. Any remaining shortfall is implicitly guaranteed by the government. Two types of equilibria emerge: One type of equilibria supports the Pareto optimal allocation. In the other type, bank lending and the default risk are excessively large. The intuition is as follows: the combination of financial intermediation by banks, limited liability of bank shareholders, and deposit insurance makes deposits risk-free from the individual households' perspective, although they involve risk from the societal point of view. This distorts investment choices and the resulting input allocation to production sectors. We show, however, that a judicious combination of deposit insurance and reinsurance eliminates all non-optimal equilibrium allocations. Our paper thus may
\end{abstract}

We would like to thank a referee, Markus Brunnermeier, Salomon Faure, Volker Hahn, Peter Howitt, Marina Iozef, George Pennacchi, Jean-Charles Rochet, O. Griffith Sexton, Eva Terberger, Jan Wenzelburger, seminar participants at ETH Zurich, Academia Sinica, University of Macau, Princeton University, Virginia Tech, and attendees at the award ceremony of the Walter Saxer Prize 2016 for their helpful comments. An earlier working paper version of this article has been circulated under the title "Deposit Insurance in General Equilibrium".

$凶$ Hans Gersbach

hgersbach@ethz.ch

Volker Britz

vbritz@ethz.ch

Hans Haller

haller@vt.edu

1 CER-ETH - Center of Economic Research at ETH Zurich, Zürichbergstrasse 18, 8092 Zurich, Switzerland

2 CER-ETH - Center of Economic Research at ETH Zurich and CEPR, Zürichbergstrasse 18, 8092 Zurich, Switzerland

3 Department of Economics, Virginia Tech, Blacksburg, VA 24061-0316, USA 
provide a benchmark result for policy proposals advocating deposit insurance cum reinsurance.

Keywords Financial intermediation · Deposit insurance · Capital structure · General equilibrium $\cdot$ Reinsurance

JEL Classification D53 $\cdot$ E44 · G2

\section{Introduction}

\subsection{Motivation}

Many countries have some form of deposit insurance for demand deposits, up to some fixed amount per account or per individual. Such deposit insurance may be either implicit or explicit. During the financial crisis of 2007-2009, it was a common practice for governments to guarantee deposits implicitly by bailing out many banks. With explicit deposit insurance, banks are required to pay an insurance premium to a deposit insurance fund. This fund is used to reimburse bank depositors in case a bank fails to honor its obligations. Several countries have a long history of explicit deposit insurance schemes. In the US, for instance, federal deposit insurance started under the (Glass-Steagall) Banking Act of 1933 which created the Federal Deposit Insurance Corporation (FDIC) in charge of insuring deposits at commercial banks. ${ }^{1}$ Deposit insurance also plays a dominant role in Europe and there are current plans for a European Union-wide deposit insurance coupled with a reinsurance scheme. ${ }^{2}$ Both deposit insurance and reinsurance are the focus of this paper.

Deposit insurance has obvious benefits. It protects small, risk-averse and potentially unsophisticated savers. It prevents bank runs and fosters financial stability. Bail-outs as implicit deposit insurance can prevent inefficient liquidation of real investments. A drawback of deposit insurance, however, is that it may lead to severe distortions. Calomiris and Jaremski (2016) provide a comprehensive historical account of the economic and political theories of deposit insurance. They conclude that in general, deposit insurance tends to increase systemic risk, rather than reducing it. Lucas (2019) provides estimates of the magnitude of public transfers associated with deposit insurance.

Conceptually, it is clear that implicit deposit insurance may encourage excessive risk-taking and excessive balance sheet expansion. But it is less clear how distortions may arise from explicit deposit insurance. Indeed, a substantial literature, which we are going to discuss in this section, has investigated whether excessive risk-taking is avoided if deposit insurance is made explicit and how deposit insurance should be priced.

\footnotetext{
1 A thorough discussion of this scheme can be found in Pennacchi (2009).

2 The European Commission's proposal of November 2015 is available at https://ec.europa.eu/info/ publications/commission-proposal-european-deposit-insurance-scheme-edis_en and amendments to the proposal from 2017 can be found at http://ec.europa.eu/finance/docs/law/171011-communication-bankingunion_en.pdf.
} 
In the present paper, we use a general equilibrium approach and add the following insights. First we examine how bank capital structures endogenously emerge in the presence of explicit deposit insurance. Next, we demonstrate that distortions cannot be avoided by explicit deposit insurance, due to multiplicity of equilibria. Finally, we show that these distortions are avoided if explicit deposit insurance is suitably combined with reinsurance.

We shall proceed with introducing the approach, outlining the results and their intuitions, drawing broader policy implications and relating the findings to the literature.

\subsection{Model}

We study deposit insurance and reinsurance in a simple general equilibrium framework with two periods $(t=1,2)$ and two sectors of production. We follow Bolton and Freixas (2000) and Gersbach et al. (2015) in their modeling of the economy's production side and introduce insurance of bank deposits. The model economy's basic characteristics are as follows:

- There is a continuum of risk-averse households and a continuum of banks. Households invest in the capital market and in banks via bonds, bank deposits and bank equity. There are two technologies for real investments. Both technologies convert the investment good at $t=1$ into the consumption good at $t=2$. One technology is risk-free, and leads to deterministic returns. In contrast, the risky technology leads to state-contingent returns, and we focus simply on two states of the world: good and bad realization of returns.

Likewise, there are two sectors of production: The risk-free sector consists of a continuum of firms working with the risk-free technology, while the risky sector consists of a continuum of firms working with the risky technology. Households can invest directly in the risk-free sector, while investment in the risky sector requires intermediation by banks. Banks are free to invest in both sectors. A detailed motivation for considering such technologies can be found in Bolton and Freixas (2000). The basic idea is as follows: Firms in the risk-free sector can be interpreted as well-established businesses, while firms in the risky sector can be viewed as young innovative firms whose entrepreneurs are subject to "moral hazard" when their activities are not monitored. Banks have appropriate monitoring ability, while households do not.

- Bank failures are assumed to be costly, i.e., liquidation of banks yields less consumption goods than production with healthy banks. Avoiding bank failures is achieved by explicit deposit insurance and works as follows: Banks pay premia to a deposit insurance fund. If banks are unable to repay depositors (even after wiping out their equity that has limited liability), then the deposit insurance fund compensates depositors for the shortfall. If even the deposit insurance fund is unable to cover the losses completely, then the government is committed to provide a bail-out for the remaining shortfall. Such a government bail-out is financed by taxing households. ${ }^{3}$

\footnotetext{
3 While we focus on costly liquidation as a reason for deposit insurance, other rationales for deposit insurance could be introduced as well as and are discussed in Sect. 3.1.
} 
In order to focus on the design and effects of deposit insurance, it is useful to assume favorable manifestations of some other potential frictions and distortions in the economy. In particular, we make the following assumptions:

- Banks act as delegated monitors and can eliminate moral hazard problems in the risky sector. ${ }^{4}$ Banks are therefore essential for the financing of the risky sector. For simplicity, we set monitoring costs to zero. We discuss in the concluding section that the underlying logic holds more generally and how moral hazard and costs of monitoring can be incorporated in the analysis.

- When a government bail-out is needed, the required taxation of households is lump sum and therefore does not lead to additional distortions.

Given this set-up, it is a priori unclear whether equilibria in such an economy yield the optimal allocations that would occur in an Arrow-Debreu version of the economy. Moreover, it is unclear which form of deposit insurance is conducive to welfare and whether bail-out of defaulting deposit insurance funds or reinsurance is preferable.

\subsection{Main results, intuition and policy perspectives}

We establish the following sequence of results: In the set-up with deposit insurance but without reinsurance, two classes of equilibria exist. In one class, bank equity completely absorbs losses in bad times and deposit insurance is redundant. The allocation is optimal in the sense that it maximizes the aggregate utility of households and coincides with the allocation achieved in the Arrow-Debreu version of the model. ${ }^{5}$

In a second class of equilibria, banks default in the bad state and equilibrium allocations are not optimal. In this class, we have a continuum of equilibria with different allocations and welfare levels. This class of equilibria exists with actuarially fair deposit insurance schemes and even when additional systemic surcharges on deposit insurance premia are imposed. In the event of a banking crisis, deposit insurance schemes cannot bear the entire burden to guarantee deposits and additional government bail-outs financed through taxation become necessary.

It is worth emphasizing that the model economy with financial intermediation and deposit insurance admits a continuum of equilibria with different allocations and welfare levels, while the standard Arrow-Debreu economy without financial intermediation has a unique equilibrium. ${ }^{6}$ We next develop an intuition for this result.

Above a certain debt-equity ratio, a continuum of non-optimal equilibria arises. While too little is invested in the risk-free sector, generating high returns on safe

\footnotetext{
${ }^{4}$ Entrepreneurs in the risky sector then only play the passive role of running the technology. There is also no moral hazard on the part of bank managers monitoring entrepreneurs in the basic model.

5 Throughout the paper, we will use the terms "optimal" and "non-optimal" in this sense. We reserve the term "efficient" in order to refer to an allocation which maximizes (expected) output in the economy. In the next section, it will be made clear that optimality and productive efficiency do not coincide in our model.

6 The latter holds because there exists a representative household which under standard assumptions implies a unique optimal allocation and a unique equilibrium allocation. While in general, real indeterminacy can occur in the traditional Arrow-Debreu model, all equilibrium allocations are optimal. However, if default is possible, then with complete markets, coexistence of optimal and sub-optimal equilibrium allocations may obtain as well. In contrast, with incomplete markets the possibility of anticipated default may enlarge the space of feasible allocations and enhance equilibrium welfare, as Zame (1993) has shown.
} 
assets, there is over-investment in the risky sector and banks raise too many funds. Such a situation is an equilibrium, as this investment pattern is consistent with the optimal portfolio choice of risk-averse households. Households anticipate that they have to pay taxes in the bad state to bail out banks and that they receive additional funds from the deposit insurance fund in the good state. Hence, households already face risks they cannot avoid and thus are only willing to invest an additional small amount in bank equity, which, in turn, is more volatile than in the no default equilibria. In contrast, since the safe investment in banks via deposits is more attractive than in the no default equilibria, households are willing to invest a large amount in bank deposits. Hence, the relatively small amount of investments in risky bank equity and the large amount in safe bank deposits is consistent with households' optimal portfolio choice. In total, banks receive more funding in the form of deposits and end up with less equity at the same time, which results in a high debt-equity ratio. Since banks invest all their funds in the risky technology, over-investment occurs in that sector, too little investment in the frictionless sector and a non-optimal allocation of resources overall.

In order to avoid non-optimal equilibrium allocations associated with deposit insurance schemes of any type, deposit insurance must be coupled with a reinsurance provision. With a reinsurance provision, the deposit insurance fund writes reinsurance contracts with households. That is, the deposit insurance fund pays one unit of the investment good per contract to households after it has itself collected the deposit insurance premium from banks in period $t=1$. If the bad state realizes in period $t=2$, households pay an amount per contract to the deposit insurance fund. The payment per contract in such cases is determined in equilibrium.

We show that a specific combination of deposit insurance and reinsurance (provided via the capital market or through reinsurance firms) guarantees an optimal allocation in any equilibrium. There may still be equilibria with banking crises, but those crises are immediately resolved through deposit insurance and reinsurance without government intervention. The key insight is that the amount of reinsurance contracts is linked to the capital structure (and deposit insurance premia) of banks such that no transfer from and to the deposit insurance fund is needed in good and bad states, respectively. Hence, the household's problem becomes effectively equivalent to the one without financial intermediation.

However, this only works at a particular capital structure of banks which, in turn, is uniquely pinned down in equilibrium. The reason is that a particular debt-equity ratio is associated with a particular amount of losses in the bad state due to limited liability of equity holders which, in turn, has to be covered by reinsurance. Only if the implied mix of risky and safe assets is consistent with the choice of households, can a bank capital structure qualify to be part of an equilibrium. This in turn pins down the capital structure. Hence, as a further consequence, we show that there exists a unique socially optimal deposit insurance scheme that supports the equilibrium. Hence, reinsurance also eliminates the multiplicity of equilibria - or real indeterminacy, to be precise.

Whereas the results will be derived in a general equilibrium setting, under certain assumptions on technologies and preferences, we argue in the concluding section that the underlying logic holds true more generally for economies with banks and aggregate risk. 


\subsection{Relation to the Literature and Policy Perspectives}

Our paper is closely related to several strands in the literature, most notably the literature on pricing deposit insurance and endogenous bank capital structures. One important challenge in designing explicit deposit insurance schemes is to determine the adequate price of the insurance. An influential early literature has addressed the question how to price deposit insurance; see, e.g., Merton (1977, 1978), Marcus and Shaked (1984), McCulloch (1985), Ronn and Verma (1986), and Flannery (1991). Its limits are outlined in Chan et al. (1992) and regulatory forbearance in closing banks is addressed in Allen and Saunders (1993) and Dreyfus et al. (1994). The work by Freixas and Rochet (1998) indicates that pricing of deposit insurance can be undesirable in adverse selection environments, since it entails subsidization of less efficient banks by the most efficient ones. One standard approach is to aim for an actuarially fair premium. Recent contributions by Pennacchi (2006) and Acharya et al. (2010) have shown that actuarially fair pricing of deposit insurance at the level of an individual bank is insufficient since banks do not represent a pool of stochastically independent risks. The reason is that bank failures tend to occur during downturns, or are widespread in a banking crisis. These insights suggest that it might be appropriate to add a "systemic risk surcharge" to the actuarially fair premium.

Two rationales for imposing surcharges have been provided. First, as derived in Pennacchi (2006), premia must exceed expected losses, since the deposit insurer bears aggregate risk. Without such charges for systemic risk, insured deposits would be subsidized compared to uninsured funding. This, in turn, may lead to excessive expansion of risky investments by commercial banks that are financed by insured deposits.

Second, in a systemic crisis the deposit insurance fund faces particularly low liquidation values of assets of failing banks because of fire sales and bank interconnectedness (Acharya et al. (2010), Allen and Gale (2000) and Kahn and Santos (2005)). The shortfall per dollar of insured deposits is larger than when only one or few banks default. Hence, to cover the expected losses, the deposit insurance premium must be higher than actuarial fairness at the level of the individual bank in isolation would suggest. In other words, the assessment of an actuarially fair deposit insurance premium must be based on the risk of individual bank failures together with the risk of widespread bank failures. ${ }^{7}$

In this paper, we take a complementary view by focusing on general equilibrium feedback effects of deposit insurance and how deposit insurance affects the capital structures of banks. Moreover, we offer a deposit insurance scheme, coupled with reinsurance, that guarantees socially optimal allocations in all equilibria. The paper thus may provide a benchmark result for policy proposals that favor some form of reinsurance as a complement to deposit insurance.

Our work is also complementary to earlier general equilibrium approaches to deposit insurance. Boyd et al. (2002) have highlighted that changes in deposit insurance pricing can be outweighed by changes in deposit rates of return and thus may

\footnotetext{
7 Acharya et al. (2010) further show that incentive-efficient risk premia that discourage banks to take excessive correlation risk are even higher than the actuarially fair premia.
} 
have no impact on bank lending in a simple general equilibrium setting. ${ }^{8}$ Standard propositions such as the desirability of actuarially fair pricing or undesirability of subsidization of banks through deposit insurance may therefore not hold.

While Boyd et al. (2002) focus on banks using debt contracts, we develop a general equilibrium model in which households choose a portfolio of debt and bank equity structures. ${ }^{9}$ Bank equity acts as a buffer against losses. We study how bank capital structures and associated probabilities of bank failures endogenously emerge in the presence of deposit insurance and reinsurance.

Our analysis also complements Allen et al. (2015) on endogenous bank capital structures. Their model treats the cost of equity and deposit finance as endogenous, and provides a rationale for capital regulation in an environment with deposit insurance. In our two-sector model, we develop a rationale for complementing deposit insurance with a reinsurance scheme. One feature of our model is that we obtain a multitude of equilibria. This is due in part to the decreasing marginal returns in a production sector that uses a risk-free technology.

Finally, over the last decades, several authors have advocated reinsurance as a complement to deposit insurance in order to avoid or reduce government bail-outs. Plaut (1991) and Sheehan (2003) have outlined possible reinsurance solutions, and Madan and Unal (2008) have examined the pricing of reinsurance contracts. Also the establishment of a European Deposit insurance scheme (EDIS) involves reinsurance in particular phases as mentioned at the beginning of the paper. We provide a general equilibrium benchmark result and suggest that a judicious combination of deposit insurance and reinsurance eliminates all non-optimal equilibrium allocations and avoids government bail-outs_although banking crises can still occur. These crises, however, are resolved quickly and anticipating them does not distort the investment allocation in the economy.

The paper is organized as follows. In the next section, we outline the detailed setup of our model and characterize the Arrow-Debreu equilibrium. The details of the Arrow-Debreu equilibrium are relegated to Appendix A. In Sect. 3, we introduce banks and deposit insurance and develop the corresponding equilibrium concept. In Sect. 4, we characterize these equilibria and identify the set of equilibria supporting optimal and non-optimal allocations, respectively. In Sect. 5, we introduce reinsurance and show that the ensuing equilibrium allocation is unambiguously optimal. Section 6 concludes. Appendix B contains the proofs. Appendix C examines the possibility of too little risk-taking by banks.

\footnotetext{
${ }^{8}$ In Boyd et al. (2004), they show that this line of reasoning has to be altered in a monetary setting with reserve requirements.

9 For other important general equilibrium theories of debt and equity financing see Jerman and Quadrini (2012).
} 


\section{An economy without financial intermediation}

\subsection{Production side}

We start with the description of the production side of our two-period model. The periods are denoted by $t=1,2$. There is a continuum of measure one of identical households initially endowed with an amount $\omega>0$ of an investment good. The investment good cannot be consumed or stored. For convenience, we use the variable $\omega$ for both the per capita endowment of households and for the aggregate endowment with the investment good in the economy.

There are two technologies by which the investment good at $t=1$ can be transformed into a consumption good at $t=2$. The risk-free technology transforms $y$ units of investment good into $f(y)$ units of consumption good. The production function $f(y)$ is twice continuously differentiable, strictly increasing, strictly concave, and satisfies the lower and upper Inada conditions $\lim _{y \downarrow 0} f^{\prime}(y)=+\infty$ and $\lim _{y \uparrow \omega} f^{\prime}(y)=0$. The returns of the risky technology are contingent on the state of nature. The state of nature at $t=2$ belongs to the state space $\{g, b\}$, i.e., the state of nature can be "good" or "bad." It is common knowledge that state $g$ occurs with probability $\sigma$, and state $b$ occurs with complementary probability $1-\sigma$.

The risky technology transforms $y$ units of investment good into $y \bar{R}$ units of consumption good in state $g$, and into $y \underline{R}$ units of consumption good in state $b$, where $\bar{R}>\underline{R} \geq 0$. The expected return of investing one unit of investment good in the risky technology is

$$
\sigma \bar{R}+(1-\sigma) \underline{R}
$$

It is important to stress that, due to households' risk-aversion, the optimal allocation is not characterized by an equal expected marginal product in both sectors. We will give a detailed characterization of the optimal allocation in Appendix A.

Notice also that we have assumed decreasing returns to scale in one technology and constant returns to scale in the other technology. The role of these assumptions is to guarantee an interior solution for the optimal allocation of investment to the two sectors. In principle, such an interior solution could also be achieved if we assumed decreasing returns in both sectors, or if we assumed constant returns in the risk-free firms, and decreasing returns in the risky technology. However, our current setup is the most tractable modeling choice.

In the sequel, we denote by $\left(y_{M}, y_{F}\right)$ the factor demands in the risky and risk-free sectors, respectively. The Inada conditions imposed on the production function $f(y)$ ensure existence of interior solutions. However, the assumption is more stringent than needed. For instance, the upper Inada condition may be replaced by $f^{\prime}(w)<\underline{R}$. In each sector of production, there is competition among a continuum of small and identical firms who maximize profits while taking all aggregate economic variables (and in particular, prices) as given. ${ }^{10}$ Therefore, it is appropriate to focus the analysis on a representative firm for each sector.

\footnotetext{
10 In the case of risk-free technology, one often assumes that each firm operates a project of size one and productivities are project-specific. The distribution of firm productivities generates the function $f\left(y_{F}\right)$.
} 
We assume complete contingent commodity markets-or, equivalently, complete asset structures. For this purpose, we introduce the price vector $\left(1, p_{g}, p_{b}\right)$, where the price of the investment good has been normalized to one. The price at $t=1$ for obtaining one unit of the consumption good in the good state and nothing in the bad state is denoted by $p_{g}$. The price at $t=1$ for obtaining one unit of the consumption good in the bad state and nothing in the good state is denoted by $p_{b}$. The profit function of the representative firm in either sector is given by:

$$
\begin{gathered}
\Pi_{F}\left(y_{F}, p_{g}, p_{b}\right)=\left(p_{g}+p_{b}\right) f\left(y_{F}\right)-y_{F}, \\
\Pi_{M}\left(y_{M}, p_{g}, p_{b}\right)=\left(p_{g} \bar{R}+p_{b} \underline{R}-1\right) y_{M} .
\end{gathered}
$$

Since the representative firm in either sector is a price-taker, it considers $p_{g}$ and $p_{b}$ as given and treats its factor demand as its decision variable. Indeed, choosing $y_{F}$ and $y_{M}$ in order to maximize the representative firms' profits leads to the conditions

$$
\begin{aligned}
\left(p_{g}+p_{b}\right)^{-1} & =f^{\prime}\left(y_{F}\right), \\
p_{g} \bar{R}+p_{b} \underline{R} & =1 .
\end{aligned}
$$

Observe that competitive markets and constant returns to scale in the risky sector imply that $\Pi_{M}=0$ in equilibrium. If condition (2) did not hold, the demand for the investment good of the representative firm would be zero or infinite, which cannot occur in equilibrium. In the risk-free technology sector, however, the profit $\Pi_{F}>0$ is strictly positive despite perfect competition because of decreasing returns to scale.

\subsection{Consumer side}

All households have identical preferences over consumption pairs $\left(c_{g}, c_{b}\right)$ where $c_{g}\left(c_{b}\right)$ is the consumption in the good (bad) state, with $\left(c_{g}, c_{b}\right) \in \mathbb{R}_{+}^{2}$. These preferences are represented by a utility function $U\left(c_{g}, c_{b}\right)$ which is additively separable across states and exhibits constant relative risk aversion. Formally, we assume that

$$
\begin{aligned}
U\left(c_{g}, c_{b}\right) & =\sigma u\left(c_{g}\right)+(1-\sigma) u\left(c_{b}\right), \\
u\left(c_{s}\right) & =(1-\theta)^{-1} c_{s}^{1-\theta}, s=g, b,
\end{aligned}
$$

with $\theta>0$ and $\theta \neq 1$.

All households are equally endowed with ownership of the risk-free technology and risky technology firms. Due to market completeness, we need not model any trade in the ownership shares of the firms. Under these assumptions, we can proceed as if there was a single representative household with utility function $u$ and an initial endowment $\omega>0$ of the investment good. The profits of firms in both sectors are denoted by $\Pi_{F}$ and $\Pi_{M}$, where we have already argued that $\Pi_{M}=0$. Profits are distributed equally to all households, so that the representative household has a budget set

$$
\mathcal{B}\left(\Pi_{F}, p_{g}, p_{b}\right)=\left\{\left(c_{g}, c_{b}\right) \in \mathbb{R}_{+}^{2} \mid w+\Pi_{F} \geq p_{g} c_{g}+p_{b} c_{b}\right\} .
$$


The household seeks to maximize utility over this budget set, which leads to the first-order condition

$$
\left(\frac{c_{g}}{c_{b}}\right)^{\theta}=\left(\frac{p_{b}}{p_{g}}\right)\left(\frac{\sigma}{1-\sigma}\right) .
$$

\subsection{Equilibrium without financial intermediation}

Before discussing frictions and the role of banks, it is helpful to consider a simple economy without financial intermediation as a benchmark. In that economy, households can directly finance the representative firms in both sectors of production, and all agents trade in complete contingent commodity markets. In Appendix A, we provide a detailed characterization of the Arrow-Debreu equilibrium for this economy. We refer to this notion of equilibrium as an equilibrium without financial intermediation. Here, we only summarize two results from Appendix A that are important for understanding and benchmarking the subsequent results.

\section{Theorem 1}

(i) The tuple $\left(c_{g}^{*}, c_{b}^{*}, y_{F}^{*}, y_{M}^{*}\right) \gg 0$ is part of an equilibrium without financial intermediation if it solves the following system of equations:

$$
\begin{aligned}
y_{M} & =\omega-y_{F}, \\
c_{g} & =f\left(y_{F}\right)+y_{M} \bar{R}, \\
c_{b} & =f\left(y_{F}\right)+y_{M} \underline{R}, \\
\left(\frac{c_{g}}{c_{b}}\right)^{\theta} & =\left(\frac{\sigma}{1-\sigma}\right)\left(\frac{\bar{R}-f^{\prime}\left(y_{F}\right)}{f^{\prime}\left(y_{F}\right)-\underline{R}}\right) .
\end{aligned}
$$

(ii) An equilibrium without financial intermediation yields the optimal allocation.

The second result is of course the manifestation of the first welfare theorem for a production economy with risk. Note that the equilibrium in Theorem 1(i) specifies the input allocation and the consumption allocation, respecting the production plans, and thus the complete commodity allocation. For later reference, we denote the ArrowDebreu equilibrium values by $\widehat{p}_{g}, \widehat{p}_{b}, \widehat{c}_{g}, \widehat{c}_{b}, \widehat{y}_{F}, \widehat{y}_{M}$, and $\widehat{\Pi}_{F}$.

We note that the optimality condition for households in Theorem 1(i) can be equivalently rewritten as

$$
\left[(1-\sigma) c_{b}^{-\theta}+\sigma c_{g}^{-\theta}\right] f^{\prime}\left(y_{F}\right)=(1-\sigma) c_{b}^{-\theta} \underline{R}+\sigma c_{g}^{-\theta} \bar{R}
$$

Verbally, the expected marginal utility from investment is the same in both sectors. In the sequel, the allocation characterized by Theorem 1 serves as a benchmark as we discuss economies with frictions caused by financial intermediation as well as deposit insurance. 


\section{An economy with banks and deposit insurance}

\subsection{Model description}

From now on, we will add two new features to the model: First, we assume that households can invest directly in the risk-free sector, but any investment in the risky sector requires financial intermediation by banks. More specifically, financing of firms in the risky sector is plagued by moral hazard. In the simplest case, these firms may simply not pay back. Banks can alleviate this moral hazard problem by monitoring borrowers and enforcing contractual obligations. ${ }^{11}$

Second, there is a continuum of banks. Contrary to the earlier benchmark economy without financial intermediation, households do not invest directly in the risky technology but provide funds to banks as deposits and as equity. Banks act in the interest of their shareholders who have limited liability for losses. Moreover, the government is committed to ensuring the viability of the banking system. More specifically, bank failures $^{12}$ impose positive liquidation costs of $\bar{L}$ and $\underline{L}$ in the good and bad state of the world, respectively with $\underline{L}<\underline{R}$ and $\bar{L}<\bar{R}$. To avoid these liquidation costs the government introduces a deposit insurance scheme with a deposit insurance fund which operates as follows. In period $t=1$, banks must contribute a certain share of their deposits as a premium to the deposit insurance fund. The deposit insurance fund invests the premium in the risk-free technology sector. ${ }^{13}$ If a bank fails to repay its depositors in period $t=2$, then, as a first step, bank equity is wiped out. Once all equity has been wiped out, the deposit insurance fund reimburses depositors. If even the deposit insurance fund does not have sufficient means to compensate the depositors, then the government repays deposits and finances this bail-out by a lump-sum tax on all households. If the deposit insurance fund is not depleted in the second period, then the remaining funds are distributed equally to all households.

Several remarks are in order. First, the deposit insurance scheme is motivated from a normative perspective by high social costs when many banks fail simultaneously. However, since explicit deposit insurance schemes are widespread in reality, our investigation could also be motivated from a positive perspective and by the questions: Which distortions arise from explicit deposit insurance and which complementary measures and regulations may be able to neutralize potential welfare? Reinsurance as addressed in our paper is an example for such complementary measures. Second,

\footnotetext{
11 One interpretation is to think of the risky sector as an industry where firms are subject to moral hazard, and the necessary monitoring and contract enforcement can only be done by banks and not by households. See Freixas and Rochet (2008) for a comprehensive account of the microeconomic foundations of financial intermediation, and Diamond (1984) for the foundation of banks as delegated monitors.

12 Since all banks behave in the same way, bank failures in our model correspond to the collapse of the entire banking system and the costs of bank failures are assumed to be caused by this collapse.

13 This requirement is important. Allowing the deposit insurance fund to invest in the risky technology would mean that the deposit insurance has less funds available precisely when they are needed to repay depositors.
} 
avoiding bank failures could also be justified by a desire to protect a class of extremely risk-averse depositors. ${ }^{14}$

Explicit deposit insurance schemes introduce potential distortions, since households may be taxed in the bad state and receive refunds from the deposit insurance fund in the good state. In order to focus on the aforementioned distortions, we make three additional assumptions to rule out other sources of friction: First, we assume that banks can monitor the representative risky technology firm perfectly at zero costany moral hazard at the bank level is eliminated. Second, we assume that the bank acts in the best interest of its shareholders/equity-holders. In particular, there is no friction between the interests of the bank managers as agents and the shareholders as principals. In the last section, we outline how moral hazard of bank managers can be integrated in our analysis. Third, we only consider lump-sum taxation of and lump-sum refunds to households, thus eliminating any tax distortions.

As before, all individual actors in the economy (households, firms, and banks) are atomic and, therefore, ought to be treated as price (or contract) takers. We will now discuss in turn the relevant optimization problems of firms, banks, and households.

\subsection{Firms}

Households still invest directly in the risk-free sector. More formally, we will say that risk-free technology firms issue bonds to households. The bond obliges the firm to pay an amount $R_{F}$ to the household in the second period, while its purchase price is normalized to one. Risk-free firms maximize profits by an appropriate choice of the factor demand $y_{F}$. That is, a risk-free firm solves the optimization problem $\max _{y_{F}} f\left(y_{F}\right)-R_{F} y_{F}$. It is straightforward that the solution of this problem satisfies

$$
R_{F}=f^{\prime}\left(y_{F}\right)
$$

Under an appropriate notion of equilibrium, risk-free firms maximize their profits, and so the above equality holds. In what follows, we will use the notation $R_{F}$ for the risk-free rate and, equivalently, for the marginal return on the risk-free technology, whenever no confusion arises.

It does not imply, however, that we can use $R_{F}$ and $f^{\prime}\left(y_{F}\right)$ completely interchangeably. In particular, whenever it is not yet established that some value of $y_{F}$ is part of an equilibrium, we cannot simply replace $f^{\prime}\left(y_{F}\right)$ with the notation $R_{F}$.

Now consider the risky sector. For the representative risky firm, the only channel of funding is financial intermediation by banks. Due to perfect monitoring, banks can enforce the terms of the loan contract and make loan repayment rates contingent on

\footnotetext{
14 Suppose that in addition to the class of households present in our formal model there is a second continuum if households that are extremely risk-averse, lack the financial literacy to invest in all assets and only concentrate their savings on bank deposits and their risk. Then, introducing deposit insurance increases welfare of this retail household group (interested only in the traditional retail services of banks) as risky deposits are avoided. Hence, our investigation can be understood as ways to create safe deposits for retail households with simultaneous instruments to limit or even eliminate potential welfare losses for the first class of households. Formal details of the version with two classes of households which may also preclude the possibility to eliminate non-optimal equilibria via capital requirements are available upon request.
} 
the state. We claim that equilibrium repayment of loans by the representative firm is given as follows: In the good state, the firm repays $\bar{R}$ per unit, and repayment in the bad state is $\underline{R}$. If the pair of repayment rates was different from $(\bar{R}, \underline{R})$, then a risky firm would either demand an infinite amount of funds or no funds from banks. The former case occurs if at least one contingent repayment rate is below the equilibrium rate. The latter occurs if both repayment rates are higher than the equilibrium rate and one is strictly higher. ${ }^{15}$ With equilibrium repayment rates $(\bar{R}, \underline{R})$ the representative risky firm makes zero profits in equilibrium, reflecting the outcome under perfect competition with constant returns to scale technology.

\subsection{Banks and deposit insurance}

There is a continuum of identical banks that are financed by (outside) equity and interest bearing deposits. The total amounts of debt and equity in the economy are equally distributed to all banks, and denoted by $D$ and $E$. Therefore, we proceed by considering only one representative bank receiving deposits $D$ and equity $E$ and acting competitively. ${ }^{16}$ Given that the price of the investment good has been normalized to one, and $D$ and $E$ are expressed in terms of investment good, one can alternatively think of $D$ and $E$ as the number of debt and equity contracts in the economy.

We will make use of an equilibrium concept which requires equilibrium variables, such as $D$ and $E$, to be strictly positive. Requiring $D>0$ simplifies the technical analysis, but it is not essential for the results since allowing $D=0$ just adds a "full equity" equilibrium to the class of equilibria with optimal allocations. Our main results, however, pertain to the existence or non-existence of equilibria with nonoptimal allocations.

Moreover, we do not consider cases with zero equity since otherwise banks are not legal entities and cannot operate. This is in line with common practice for regulators to require a certain amount of equity for a bank to be founded and to obtain a banking license. ${ }^{17}$ Moreover, a situation with zero equity would be inconsistent with equilibrium in our model as the return on equity can grow without bound as equity tends to zero.

Let $R_{D}$ be the (gross) rate of return on deposits. That is, for every unit of deposits, the bank pays $R_{D}$ in the second period. Deposits are risk-free due to (explicit and implicit) deposit insurance. Due to a standard arbitrage argument, the return on all risk-free assets in the economy must be equal if households make an optimal portfolio choice. Formally, we have

\footnotetext{
15 One could consider a scenario when the risky firm accepts one or two higher contingent repayment rates and would default if it cannot repay. If bankruptcy imposes no costs on firms or does not reduce the investment returns, such a constellation would lead to the same effective repayment rates $\bar{R}$ and $\underline{R}$, respectively.

16 The capital structure of the representative bank is supply determined, i.e., banks are willing to accept all resources they are offered in the form of deposits. However, the optimal and non-optimal equilibria we will derive continue to exist if banks actively choose their capital structure as will be discussed in Sect. 4.5. 17 To give one example, the European Union requires an initial capital stock of equity not less than EUR 5 million, see Article 12 of Directive 2013/36 EU.
} 


$$
R_{D}=R_{F},
$$

where we recall that $R_{F}$ is the rate of return on bonds. In what follows, we will often write $R_{F}$ when we mean the risk-free return in the economy.

Deposit insurance works as follows: A bank has to contribute a share $\delta \in[0,1]$ of its deposits to the deposit insurance fund (DIF). The DIF then invests the amount $\delta D$ in safe assets, i.e., in the risk-free technology sector. If the bank is able to honor its obligations towards depositors at $t=2$, then the funds of the DIF are distributed to households. If banks cannot honor their obligations towards depositors, then the DIF reimburses the depositors. If the funds of the DIF are insufficient for this purpose, then the government provides a bail-out for the remaining deposits financed by a lump-sum tax on households.

We consider the problem of the representative bank. With the exception of Sect. 4.5, the capital structure of banks is determined by the portfolio choices of households, while banks only choose their investments. Given that the representative bank has obtained $D$ and $E$, the objective is to maximize the payoff to its shareholders. The choice variable is the share $\alpha \in[0,1]$ which the bank invests in risky technology, while the complementary share $1-\alpha$ is invested in risk-free technology. Due to perfect competition, the representative bank takes the prices prevailing in the economy as given.

We next consider the formal problem of the representative bank that aims at maximizing the expected payoff to bank shareholders. Taking into account that shareholders are not liable for losses, their payoffs in the good and bad state are given by:

$$
\begin{aligned}
& \bar{\pi}(\alpha)=\max \left\{0,\left(\alpha \bar{R}+(1-\alpha) R_{F}\right)((1-\delta) D+E)-R_{F} D\right\}, \\
& \underline{\pi}(\alpha)=\max \left\{0,\left(\alpha \underline{R}+(1-\alpha) R_{F}\right)((1-\delta) D+E)-R_{F} D\right\} .
\end{aligned}
$$

We use the notation $\bar{R}_{E}(\alpha)=\bar{\pi}(\alpha) / E$ and $\underline{R}_{E}(\alpha)=\underline{\pi}(\alpha) / E$ for the return on equity in either state. Since $E$ is taken as given in the bank's optimization problem, maximizing the expected shareholder payoff is equivalent to maximizing the expected return on equity. More formally, the bank's optimization problem is:

$$
\max _{\alpha \in[0,1]} \sigma \bar{\pi}(\alpha)+(1-\sigma) \underline{\pi}(\alpha) .
$$

We are going to show that the representative bank optimally chooses $\alpha=1$, provided that households invest sufficiently in risk-free technology.

Lemma 1 Suppose that $R_{F}<\sigma \bar{R}+(1-\sigma) \underline{R}$. Then it is optimal for the bank to choose $\alpha=1$.

The proof of Lemma 1 is given in Appendix B. The condition $R_{F}<\sigma \bar{R}+(1-\sigma) \underline{R}$ holds in the first-best allocation as there is a risk-return trade-off for consumers. Under this condition, the preceding lemma shows that in any equilibrium banks invest fully in the risky technology sector. We will show, however, that under this condition both optimal and non-optimal allocations can emerge. We do not know if equilibria with 
$R_{F}>\sigma \bar{R}+(1-\sigma) \underline{R}$ exist. If such equilibria existed, the allocation would be nonoptimal—which strengthens the case for reinsurance made in Sect. 5.

\subsection{Consumer choice problem}

In this subsection, we discuss the consumer choice problem at the level of the individual household. Each household chooses a portfolio consisting of direct investment in riskfree technology, deposits, and bank equity. Since the rate of return on deposits is the same as that on direct investment in the risk-free technology sector, the household portfolio problem can be thought of as one-dimensional: The household chooses to invest some share of its funds in risk-free assets with payoff structure $\left(R_{F}, R_{F}\right)$, and the complementary share in equity, which is a risky asset with payoff structure $\left(\bar{R}_{E}, \underline{R}_{E}\right)$. One unit of either asset can be exchanged for one unit of the other asset; their price is normalized to one.

Banks are obliged to pay a share $\delta$ of their deposits to a deposit insurance fund. We require this fund to invest the premium in the risk-free technology sector. In the good state, the entire deposit insurance fund is distributed to households. In case banks default in the bad state, the deposit insurance fund is used to repay depositors, and any remaining shortfall is financed by a lump-sum tax on all households. Formally, the deposit insurance fund leads to the following state-contingent fixed effects $\left(t_{g}, t_{b}\right)$ on household consumption:

$$
\begin{aligned}
& t_{g}=\delta D R_{F}, \\
& t_{b}= \begin{cases}\delta D R_{F} & \text { if }[(1-\delta) D+E] \underline{R} \geq D R_{F}, \\
{[(1-\delta) D+E] \underline{R}+\delta D R_{F}-D R_{F}} & \text { otherwise. }\end{cases}
\end{aligned}
$$

The pair $\left(t_{g}, t_{b}\right)$ is determined by the aggregate portfolio decisions of all households, but taken as given by any individual household. In addition, household consumption is enhanced by profits of firms in the risk-free technology which produce an amount $f\left(y_{F}\right)$, and need to pay their bond-holders an amount $y_{F} R_{F}$. Hence, the profit is

$$
\begin{aligned}
\Pi_{F} & =f\left(y_{F}\right)-y_{F} R_{F} \\
& =f\left(y_{F}\right)-y_{F} f^{\prime}\left(y_{F}\right)>0,
\end{aligned}
$$

which is distributed to households in either state. Since we are considering a continuum economy, the individual household not only takes $\left(t_{g}, t_{b}\right)$ and $\Pi_{F}$ as given, but also the allocation $y_{F}$, the risk-free rate $R_{F}$, and the returns on equity $\left(\bar{R}_{E}, \underline{R}_{E}\right)$.

We next consider a representative household who chooses the amount to be invested in equity. His optimization problem could be written as follows:

$$
\begin{aligned}
& \max _{E \in[0, \omega]}\left(\frac{\sigma}{1-\theta}\right)\left(E \bar{R}_{E}+(\omega-E) R_{F}+t_{g}+\Pi_{F}\right)^{1-\theta} \\
& \quad+\left(\frac{1-\sigma}{1-\theta}\right)\left(E \underline{R}_{E}+(\omega-E) R_{F}+t_{b}+\Pi_{F}\right)^{1-\theta} .
\end{aligned}
$$


We note that the solution to the above problem leaves unspecified how the funds invested in risk-free assets will be divided between bank deposits and direct investment in risk-free technology. We will see later that this division of funds will be pinned down by the price of deposit insurance. The above optimization problem leads to the following first-order condition:

$$
\left(\frac{\sigma}{1-\sigma}\right)\left(\frac{\bar{R}_{E}-R_{F}}{R_{F}-\underline{R}_{E}}\right)=\left(\frac{E \bar{R}_{E}+(\omega-E) R_{F}+t_{g}+\Pi_{F}}{E \underline{R}_{E}+(\omega-E) R_{F}+t_{b}+\Pi_{F}}\right)^{\theta} .
$$

This condition is derived using a representative household approach, where it is tacitly assumed that it is indeed optimal for households to make the same choice. Since using the representative household approach does not work in all macroeconomic environments - and indeed we will encounter such a case later on when we introduce reinsurance - we next provide an explicit proof that all households choose the same portfolio when we have only deposit insurance. In the proof of the proposition, we take the average equity investment $E$ of households as given, and express an individual household's choice as a product $\eta E$, where $\eta \in \mathbb{R}_{+}$is the actual choice variable. The proof strategy then is to establish first that all households want to choose the same $\eta$, implying that each household's individual equity investment is equal to the average $E$, and hence $\eta=1$.

Proposition 1 Suppose that each individual household chooses an optimal portfolio and that $\bar{R}_{E}>R_{F}>\underline{R}_{E}$. Then, all households choose the same portfolio, characterized by $E q$. (6).

The proof of Proposition 1 is given in Appendix B. A household's consumption can now be written as

$$
\begin{aligned}
& c_{g}=E \bar{R}_{E}+(\omega-E) R_{F}+\Pi_{F}+t_{g}, \\
& c_{b}=E \underline{R}_{E}+(\omega-E) R_{F}+\Pi_{F}+t_{b} .
\end{aligned}
$$

Using the notation $\psi=D / E$ for the debt-equity ratio and Lemma 1, we can write return on equity in the two states as

$$
\begin{aligned}
& \bar{R}_{E}=\bar{\pi}(1) / E=(1+\psi-\delta \psi) \bar{R}-\psi R_{F}, \\
& \underline{R}_{E}=\underline{\pi}(1) / E=\max \left\{0,(1+\psi-\delta \psi) \underline{R}-\psi R_{F}\right\} .
\end{aligned}
$$

Substituting for $t_{g}, t_{b}, \Pi_{F}, \bar{R}_{E}$, and $\underline{R}_{E}$ into Eqs. (7) and (8), and using the condition $\omega=y_{F}+y_{M}$ yields

$$
\begin{aligned}
& c_{g}=\bar{R}_{E} f\left(y_{F}\right)+y_{M} \bar{R}, \\
& c_{b}=\bar{R}_{E} f\left(y_{F}\right)+y_{M} \underline{R} .
\end{aligned}
$$

Verbally, households are the ultimate recipients of the risk-free technology profit and any "profit" of the deposit insurance fund, and must finance the bail-out in case the 
deposit insurance fund is insufficient to pay off depositors. Deriving the above equations for $c_{g}$ and $c_{b}$, we have verified that the entire amount of consumption goods produced by both technologies will find its way back to households.

\subsection{Pricing deposit insurance}

We next take a closer look at the deposit insurance scheme. Recall that $\delta \in(0,1)$ denotes the fraction of its deposits that a bank has to pay as insurance premium. Thus, the bank can freely choose how to invest its equity as well as a share $1-\delta$ of the deposits, while the share $\delta$ of the deposits is paid to the DIF. Due to Lemma 1 , the bank invests the entire amount $E+(1-\delta) D$ in the risky technology sector. Suppose that $D>0$ and assume, in addition, that the bank defaults in the bad state. In that case, the shortfall can be written as follows:

$$
\Lambda=D R_{F}-(E+(1-\delta) D) \underline{R} .
$$

This is the amount which the bank fails to repay to its depositors, and which would have to be compensated by the DIF. However, the funds available to the DIF equal $\delta D R_{F}$, which is the insurance premium compounded by the risk-free rate. Let

$$
\mu=\mu(\delta)=\frac{\delta D R_{F}}{D R_{F}-(E+(1-\delta) D) \underline{R}}
$$

be the cover ratio of the deposit insurance fund. Clearly, there is a one-to-one correspondence between choosing the cover ratio $\mu$ of the deposit insurance and choosing its premium $\delta$. More precisely, we find by rearranging that

$$
\delta=\frac{R_{F}-\left(1+\frac{E}{D}\right) \underline{R}}{\left(\frac{1}{\mu}\right) R_{F}-\underline{R}} .
$$

Recall that we are considering equilibria with $D, E>0$, so we have the inequality

$$
\delta<\frac{R_{F}-\underline{R}}{\left(\frac{1}{\mu}\right) R_{F}-\underline{R}},
$$

and we can see that $\delta<1$ for any $\mu \leq 1$.

One pricing mechanism for deposit insurance schemes is actuarial fairness. A deposit insurance premium is actuarially fair if the DIF expects to break even, that is, the expected shortfall is equal to the insurance premium compounded at the riskfree rate. ${ }^{18}$ In our model, an actuarially fair deposit insurance is characterized by a

18 One might also consider an alternative definition of actuarial fairness which takes the perspective of the insured party. In particular, one could define an insurance as being actuarially fair if the premium equals the expected loss, that is, if $\delta D=(1-\sigma) \Lambda$. Mutatis mutandis, the conclusions of the equilibrium analysis in Sect. 5 would remain valid. 
cover ratio of $1-\sigma$. Choosing a cover ratio $\mu>1-\sigma$ is tantamount to imposing a surcharge on the actuarially fair premium. Observe that for any $\mu<1$, the deposit insurance fund is more than exhausted in the bad state, so that a government bail-out is needed. In particular, since $1-\sigma<1$, an actuarially fair deposit insurance does not make government bail-outs dispensable. If $\mu=1$, then the DIF perfectly insures the financial system; we refer to this case as full insurance. In the sequel, we are going to demonstrate that non-optimal equilibrium allocations are possible in economies with banks and deposit insurance as long as the cover ratio is strictly less than one.

\subsection{Market clearing for investment good}

Recall that households allocate their funds to deposits, equity, and risk-free technology investment. Denote their investment in risk-free technology by $y_{F, h}$. Hence,

$$
\omega=E+D+y_{F, h}
$$

In the presence of deposit insurance, the risk-free technology sector is funded not only by households directly but also by the DIF. We continue to use the notation $y_{F}$ for the factor demand in the risk-free technology sector. Thus, the factor market clears if the following condition is satisfied:

$$
y_{F}=\delta D+y_{F, h}
$$

Using the above identity, we can rewrite the market-clearing condition as

$$
\omega=E+(1-\delta) D+y_{F}
$$

For $\mu<1$, define

$$
\mathcal{D}_{\mu}(E)=\frac{\left(\omega-y_{F}\right)\left(R_{F}-\underline{R} \mu\right)-E R_{F}}{(1-\mu) R_{F}} .
$$

To interpret $\mathcal{D}_{\mu}(E)$, recall that optimal consumer choice determines the amount of funds invested in the two risk-free assets (bank deposits and risk-free technology), but does not specify the distribution of funds between those two assets. Combining Eq. (9) and the market-clearing condition above, we can see that $\mathcal{D}_{\mu}(E)$ determines the equilibrium amount of deposits as a function of the equilibrium amount of equity in an economy where the deposit insurance covers the share $\mu$ of the shortfall in the bad state. Now we are ready for the equilibrium definition.

\subsection{Equilibrium with banks and deposit insurance}

We next introduce the equilibrium definition for arbitrary deposit insurance schemes. 
Definition 1 An equilibrium with banks and $\delta$-deposit insurance is a tuple $\left(c_{g}^{*}, c_{b}^{*}, y_{M}^{*}\right.$, $\left.y_{F}^{*}, \psi^{*}, E^{*}, \bar{R}_{E}^{*}, \underline{R}_{E}^{*}, R_{F}^{*}\right) \gg 0$ which solves the following system of equations:

$$
\begin{aligned}
\left(\frac{c_{g}}{c_{b}}\right)^{\theta} & =\left(\frac{\sigma}{1-\sigma}\right)\left(\frac{\bar{R}_{E}-R_{F}}{R_{F}-\underline{R}_{E}}\right), \\
c_{g} & =f\left(y_{F}\right)+y_{M} \bar{R}, \\
c_{b} & =f\left(y_{F}\right)+y_{M} \underline{R}, \\
y_{F} & =\omega-y_{M}, \\
y_{M} & =E+(1-\delta) \psi E, \\
\bar{R}_{E} & =(1+\psi-\delta \psi) \bar{R}-\psi R_{F}, \\
\underline{R}_{E} & =\max \left\{0,(1+\psi-\delta \psi) \underline{R}-\psi R_{F}\right\}, \\
R_{F} & =f^{\prime}\left(y_{F}\right),
\end{aligned}
$$

and, moreover, satisfies the inequalities $R_{F}<\sigma \bar{R}+(1-\sigma) \underline{R}$ and $(1+\psi) E \leq \omega$.

Equivalently, we could have included the variables $\left(t_{g}, t_{b}, \Pi_{F}\right)$ and Eqs. (4) through (8) in the equilibrium definition. As we have argued previously, either the pair of Eqs. (13) and (14) or the pair of Eqs. (7) and (8) would then become redundant. As a result, this alternative equilibrium definition would consist of three extra variables and three extra independent equations without changing anything substantive.

Let us now discuss the equations in Definition 1 in turn. Equation (12) is the condition emanating from optimal portfolio choice of the households. Equations (13) through (15) are simple market-clearing conditions. Equation (16) is a consequence of Proposition 1: Banks invest as much as possible of their equity and their deposits in risky technology, but due to the deposit insurance this is subject to the restriction that the share $\delta$ of the deposits must be paid to the fund as an insurance premium. Given such investment behavior by banks, and given that return on deposits equals the bond return $R_{F}$, it follows that return on equity in both states is given by Eqs. (17) and (18). Finally, Eq. (19) states that the rate of return on bonds corresponds to the marginal product in the risk-free technology sector.

Moreover, the equilibrium definition includes an inequality which says that household investment in deposits and equity cannot exceed the funds $\omega$ available to the household. Importantly, this inequality combined with Eq. (16) implies that in any equilibrium with banks and $\delta$-deposit insurance, we have $y_{F} \geq \delta \psi E=\delta D$. Verbally, this means that the factor demand in the risk-free technology sector is sufficiently high to absorb all the funds of the deposit insurance.

Let us focus for a moment on the first four equations in the equilibrium definition. They are analogous to the definition of an equilibrium allocation without financial intermediation except that the returns $\left(\bar{R}_{E}, \underline{R}_{E}\right)$ have taken the place of the returns $(\bar{R}, \underline{R})$. The reason is obvious: In an equilibrium without financial intermediation, households invest directly in the risky technology, whereas in the equilibrium with banks and $\delta$-deposit insurance, all risky technology investment is mediated by banks. 
The risky asset is bank equity, while the household perceives bank deposits as risk-free due to the deposit insurance.

Consider the special case of the above equilibrium definition where $\delta=0$. We call it equilibrium with banks and 0-deposit insurance. This case can be interpreted in two ways: First, it can be seen as the equilibrium concept for an economy with banks, actuarially fair deposit insurance, and government bail-out guarantees in which no default occurs. Alternatively, it can also be thought of as an equilibrium concept for an economy with banks in which deposits are guaranteed by the government but there is no deposit insurance fund.

As we will show in the next sections, the equilibria set out in Definition 1 typically involve a continuum of possible debt-equity ratios ("leverage ratios"). In Sect. 4.5 below, we show that the equilibria continue to exist when banks actively manage their capital structure, e.g. by sequentially issuing their liability claims or by selecting their individual leverage.

\section{Equilibrium analysis}

In this section, we establish two results: First, in the economy with banks and deposit insurance, the optimal allocation can be supported by a multitude of equilibria. Second, a multitude of non-optimal allocations is also consistent with equilibrium.

\subsection{Equilibria supporting the optimal allocation and an impossibility result}

Proposition 2 Suppose that the tuple $\left(c_{g}^{*}, c_{b}^{*}, y_{M}^{*}, y_{F}^{*}\right)$ is an equilibrium allocation without financial intermediation. Then, $(i)$ there exists a continuum of equilibria with banks and 0 -deposit insurance which supports $\left(c_{g}^{*}, c_{b}^{*}, y_{M}^{*}, y_{F}^{*}\right)$, and (ii) for any $\delta>0$, there does not exist an equilibrium with banks, $\delta$-deposit insurance and no default that supports $\left(c_{g}^{*}, c_{b}^{*}, y_{M}^{*}, y_{F}^{*}\right)$.

The proof of Proposition 2 is given in Appendix B.

We now define a special case of an equilibrium with banks and 0-deposit insurance in which banks are "on the brink of default" in the bad state. We call this equilibrium the critical leverage equilibrium.

Definition 2 A critical leverage equilibrium is a tuple $\left(c_{g}^{*}, c_{b}^{*}, y_{M}^{*}, y_{F}^{*}, \psi^{*}, E^{*}, \bar{R}_{E}^{*}, R_{F}^{*}\right)$ $\gg 0$ which solves the following system of equations:

$$
\begin{aligned}
\left(\frac{c_{g}}{c_{b}}\right)^{\theta} & =\left(\frac{\sigma}{1-\sigma}\right)\left(\frac{\bar{R}_{E}-R_{F}}{R_{F}}\right), \\
c_{g} & =f\left(y_{F}\right)+y_{M} \bar{R}, \\
c_{b} & =f\left(y_{F}\right)+y_{M} \underline{R}, \\
y_{F} & =\omega-y_{M}, \\
y_{M} & =E(1+\psi),
\end{aligned}
$$




$$
\begin{aligned}
\bar{R}_{E} & =(1+\psi) \bar{R}-\psi R_{F}, \\
R_{F} & =f^{\prime}\left(y_{F}\right), \\
\psi & =\frac{\underline{R}}{R_{F}-\underline{R}},
\end{aligned}
$$

and, moreover, satisfies the inequalities $R_{F}^{*}<\sigma \bar{R}+(1-\sigma) \underline{R}$ and $E\left(1+\psi^{*}\right) \leq \omega$.

The critical leverage equilibrium is unique and a special case of the equilibrium with banks and $\delta$-deposit insurance. In particular, it is that equilibrium with banks and $\delta$-deposit insurance in which all equity is wiped out in the bad state but bank default is just avoided. Since the deposit insurance does not need to refund any depositors, its premium is zero. The critical leverage equilibrium supports the optimal allocation, but it will be important as a reference point for the construction of equilibria which support a non-optimal allocation.

One important remark is in order. While there exist equilibria associated with $\delta=0$ and an optimal allocation, there are other equilibria associated with $\delta=0$ and nonoptimal allocations. This is shown next.

\subsection{Non-optimal equilibrium allocations}

We have shown that an equilibrium with banks and $\delta$-deposit insurance can replicate the optimal allocation of the equilibrium without financial intermediation. Next, we show that there also exist equilibria with banks and $\delta$-deposit insurance which support non-optimal allocations. In fact, there are circumstances in which there is no value of $\delta$ which guarantees that all equilibria under $\delta$-deposit insurance involve optimal allocations. This is the problem we aim to address by introducing reinsurance.

In Appendix A, we describe the optimal allocation as that involving an investment $\widehat{y}_{F}$ in the risk-free technology as well as a complementary investment $\omega-\widehat{y}_{F}$ in the risky technology. We are going to show in this subsection that an allocation involving a slight under-investment in risk-free technology can be supported by an equilibrium with banks and $\delta$-deposit insurance. More formally, let

$$
Y_{F}^{\prime}=\left\{y_{F} \in\left(0, \widehat{y}_{F}\right) \mid f^{\prime}\left(y_{F}\right)<\sigma \bar{R}+(1-\sigma) \underline{R}\right\} .
$$

We will show that any allocation in $Y_{F}^{\prime}$ is supported by an equilibrium for sufficiently small insurance premia. ${ }^{19,20}$

Theorem 2 For every allocation $y_{F}^{\prime} \in Y_{F}^{\prime}$ and every $\delta^{\prime}<\frac{\bar{R}-f^{\prime}\left(y_{F}^{\prime}\right)}{\bar{R}}$, there exists an equilibrium with banks and $\delta^{\prime}$-deposit insurance which supports the allocation $y_{F}^{\prime}$.

\footnotetext{
${ }_{19}$ In Appendix A, we argue that $f^{\prime}\left(\widehat{y}_{F}\right)<\sigma \bar{R}+(1-\sigma) \underline{R}$. Due to the concavity of $f$, it follows that $Y_{F}^{\prime}$ is non-empty.

${ }^{20}$ We consider equilibria which support a non-optimal allocation, in the sense that $y_{F}<\widehat{y}_{F}$. Verbally, this means that there is over-investment in the risky technology and under-investment in the risk-free technology. One may wonder if there could also be equilibria which support allocations with $y_{F}>\widehat{y}_{F}$, that is, where investment in the risky technology is lower than optimal. In such an equilibrium, $f^{\prime}\left(y_{F}\right)<f^{\prime}\left(\widehat{y}_{F}\right)<$ $\sigma \bar{R}+(1-\sigma) \underline{R}$. This is addressed in Sect. 4.4.
} 
The proof of Theorem 2 is given in Appendix B. One implication of the above theorem is that a range of non-optimal allocations can be supported by equilibria if there is no deposit insurance, that is, if $\delta=0$. Moreover, a range of non-optimal allocations can also be supported by equilibria as long as the premium $\delta$ per unit of deposits is sufficiently small. More specifically, we see from the statement of the above theorem that a non-optimal allocation $y_{F}^{\prime}$ is consistent with equilibrium if $\delta<\left(\bar{R}-f^{\prime}\left(y_{F}^{\prime}\right)\right) / \bar{R}$.

Theorem 2 implies the following proposition, which is useful because it is stated only in terms of model primitives.

Proposition 3 Non-optimal equilibrium allocations exist if the deposit insurance premium satisfies

$$
\delta<(1-\sigma)\left(\frac{\bar{R}-\underline{R}}{\bar{R}}\right) .
$$

The proof of Proposition 3 can be found in Appendix B.

We note that the above proposition implies that non-optimal equilibrium allocations exist in the special case with $\delta=0$.

So far in this subsection, we have shown that non-optimal equilibrium allocations arise for sufficiently small values of $\delta$. Now we are going to derive a condition on the cover ratio $\mu$ such that the corresponding premium $\delta$ is "sufficiently small" in that sense. We have shown before that a cover ratio of $\mu \leq 1$ corresponds to a premium

$$
\delta=\frac{f^{\prime}\left(y_{F}\right)-\left(\frac{1+\psi}{\psi}\right) \underline{R}}{\left(\frac{1}{\mu}\right) f^{\prime}\left(y_{F}\right)-\underline{R}} .
$$

Since the term $(1+\psi) / \psi$ takes values in the interval $(1, \infty)$, we have

$$
\frac{f^{\prime}\left(y_{F}\right)-\left(\frac{1+\psi}{\psi}\right) \underline{R}}{\left(\frac{1}{\mu}\right) f^{\prime}\left(y_{F}\right)-\underline{R}}<\frac{f^{\prime}\left(y_{F}\right)-\underline{R}}{\left(\frac{1}{\mu}\right) f^{\prime}\left(y_{F}\right)-\underline{R}} .
$$

Now suppose that

$$
\frac{f^{\prime}\left(\widehat{y}_{F}\right)-\underline{R}}{\left(\frac{1}{\mu}\right) f^{\prime}\left(\widehat{y}_{F}\right)-\underline{R}}<(1-\sigma)\left(\frac{\bar{R}-\underline{R}}{\bar{R}}\right) .
$$

If this inequality holds, then the previous proposition implies that we can find a nonoptimal allocation in the neighborhood of the optimal allocation $\widehat{y}_{F}$ which can be supported by an equilibrium. Suitably rearranging the above inequality, we obtain the following proposition. 
Proposition 4 A non-optimal allocation in a sufficiently small neighborhood of the optimal allocation $\widehat{y}_{F}$ can be supported by an equilibrium in the presence of a deposit insurance with any cover ratio $\mu$ such that:

$$
\mu<\frac{(1-\sigma) f^{\prime}\left(\widehat{y}_{F}\right)}{\left(\frac{f^{\prime}\left(\widehat{y}_{F}\right)-\underline{R}}{\bar{R}-\underline{R}}\right) \bar{R}+(1-\sigma) \underline{R}} .
$$

The right-hand side of the inequality in the above proposition depends only on the primitive model parameters. For any configuration of the parameters, there is a critical cover ratio below which deposit insurance cannot rule out non-optimal equilibrium allocations. We want to argue that there can be economies in which this critical cover ratio is close to one, so that even very comprehensive deposit insurance cannot rule out non-optimal equilibrium allocations. Intuitively, consider a sequence of economies such that, along this sequence, the term $\bar{R}-\underline{R}$ goes to zero. This implies that the term $f^{\prime}\left(\widehat{y}_{F}\right)-\underline{R}$ tends to zero as well. Since $f^{\prime}\left(\widehat{y}_{F}\right)<\bar{R}$, the latter convergence is "faster" than the former. Consequently, the entire fraction $\frac{f^{\prime}\left(\widehat{y}_{F}\right)-\underline{R}}{\bar{R}-R}$ tends to zero along the sequence. Moreover, the entire inequality becomes $\mu<1$, irrespective of the value of $\sigma$, provided that $1-\sigma>0$.

In the next subsection, we will state two formal results: In Proposition 5, we are going to show that non-optimal equilibrium allocations are possible in the presence of actuarially fair deposit insurance. Moreover, we are going to provide a numerical example to demonstrate that non-optimal equilibrium allocations can persist even in the presence of a deposit insurance with a $99 \%$ cover ratio.

\subsection{Non-optimalities under large cover ratios}

Proposition 5 below shows that non-optimal equilibrium allocations are possible under an actuarially fair deposit insurance. In order to prepare for the proof of this proposition, we need to make sure first that there can be economies in which the actuarially fair deposit insurance premium does not exceed the factor demand in risk-free technology. We provide two examples of economies which have this property. In the second example below, we allow that the upper Inada condition is weakened. We explore the fact that with $\mu=1-\sigma$, Eq. (9) implies $\delta D \leq \omega \cdot\left(R_{F}-\underline{R}\right)(1-\sigma) /\left(R_{F}-\underline{R}(1-\sigma)\right)$.

Example 1 Let $\omega=1, f\left(y_{F}\right)=2 \sqrt{y_{F}}-y_{F}, \theta=2, \sigma=2 / 3, \underline{R}=1 / 2, \bar{R}=2$. In this example, $\widehat{y}_{F}=1 / 4$ and we write $\widehat{R}_{F}$ for $f^{\prime}\left(\widehat{y}_{F}\right)=1$. Further, since $\omega=1$ and $\left(\widehat{R}_{F}-\underline{R}\right)(1-\sigma) /\left(\widehat{R}_{F}-\underline{R}(1-\sigma)\right)=1 / 5$, it can be achieved that the entire deposit insurance premium is invested in risk-free technology when an equilibrium with riskless rate $\widehat{R}_{F}$ or close to $\widehat{R}_{F}$ is realized.

Example 2 We set $\omega=1, \sigma=1 / 2, \theta=1 / 2, \underline{R}=0, \bar{R}=2$, and assume that $f\left(y_{F}\right)=2\left(y_{F}-\frac{y_{F}^{2}}{2}\right)$. In this example, $\widehat{R}_{F}=2 /(1+\sqrt{2})$ and $\widehat{y}_{F}=2-\sqrt{2}$. Since $\omega=1$ and $\left(\widehat{R}_{F}-\underline{R}\right)(1-\sigma) /\left(\widehat{R}_{F}-\underline{R}(1-\sigma)\right)=1 / 2<2-\sqrt{2}$, it can be achieved that 
the entire deposit insurance premium is invested in risk-free technology in equilibria with riskless rates close to $\widehat{R}_{F}$.

We next provide a proof that non-optimal equilibrium allocations can arise under actuarially fair deposit insurance. ${ }^{21}$ This will help prove that non-optimal equilibrium allocations can occur under any deposit insurance scheme.

Proposition 5 Suppose the Arrow-Debreu equilibrium allocation satisfies $\widehat{R}_{F} \leq 1$. Suppose that the deposit insurance is actuarially fair. Then there exist equilibria with financial intermediation where the investment in risk-free technology is strictly smaller than $\widehat{y}_{F}$, the investment in the risky technology is $E+(1-\delta) D$, banks only invest in the risky technology and default in the bad state. In addition to coverage by deposit insurance, government bail-out of banks is necessary in the bad state. The resulting equilibrium allocation is non-optimal.

The proof of Proposition 5 is given in Appendix B. Notice that the hypothesis of the proposition and the assumption that the deposit insurance premium does not exceed the factor demand of the risk-free sector are satisfied for certain model specifications as we have seen in Examples 1 and 2.

The argument in the proof of Proposition 5 relies on the fact that households (a) are taxed in the bad state and (b) receive a refund in the good state. Thus, the argument still applies when deposit insurance is slightly actuarially unfair. Actually, the validity of (a) or (b) suffices. Therefore, the proof of the proposition works even when deposit insurance covers a huge fraction of the banks' deficit in case of default, provided that (c) the deposit insurance can invest all its premium revenue in the risk-free sector, that is the factor demand of the risk-free sector is high enough and (d) Eq. (11) can be applied. The right-hand side of (11) is ill defined and (11) is not applicable if $\mu=1$. While (c) does not hold in general, it does hold with $\mu=0.99$ in some model specifications as the following example demonstrates.

Example 3 Let $n>1$ be a natural number. Put $\omega=1, \underline{R}=(n+1)^{1 / 2}-1, \bar{R}=$ $(n+1)^{1 / 2}, y_{F}^{+}=1-1 /(n+1), y_{F}^{0}=1-1 /(n+2)$ and

$$
f\left(y_{F}\right)= \begin{cases}2 n^{1 / 2} \cdot\left(y_{F}\right)^{1 / 2} & \text { for } y_{F} \in\left[0, y_{F}^{0}\right] ; \\ 2 n^{1 / 2} \cdot\left(y_{F}\right)^{1 / 2}-\left[n^{1 / 2} \cdot(n+2)^{3} / 4\right]\left(y_{F}-y_{F}^{0}\right)^{4} & \text { for } y_{F}>y_{F}^{0} .\end{cases}
$$

Then $\widehat{p}_{g} \bar{R}+\widehat{p}_{b} \underline{R}=1$ implies $\left(\widehat{p}_{g}+\widehat{p}_{b}\right)(n+1)^{1 / 2}>1$ and consequently $\left(\widehat{p}_{g}+\widehat{p}_{b}\right)>$ $(n+1)^{-1 / 2}$. Profit maximization in risk-free technology requires $\left(\widehat{p}_{g}+\widehat{p}_{b}\right) f^{\prime}\left(\widehat{y}_{F}\right)=1$. Now $\left(\widehat{p}_{g}+\widehat{p}_{b}\right) f^{\prime}\left(y_{F}^{+}\right)>(n+1)^{-1 / 2} \cdot n^{1 / 2} \cdot\left(y_{F}^{+}\right)^{-1 / 2}=(n /(n+1))^{1 / 2} \cdot(n /(n+$ $1))^{-1 / 2}=1$. Hence $\widehat{y}_{F}>y_{F}^{+}=1-1 /(n+1)$. Dividing $\underline{R}, \bar{R}$ and $f$ by $(4 / 3)(n+1)^{1 / 2}$ yields a model with identical $\widehat{y}_{F}$ and $(3 / 4)\left(1-(n+1)^{-1 / 2}\right)=\underline{R}<\widehat{R}_{F}<\bar{R}=3 / 4$. Next let $n=24$. Then $y_{F}^{*}=\widehat{y}_{F}>24 / 25=0.96, E^{*}=y_{M}^{*} /\left(1+\psi^{*}\right)=\widehat{y}_{M} /(1+$ $\left.\psi^{*}\right) \in(0,1 / 25)$ and $R_{F}^{*}=\widehat{R}_{F} \in(3 / 5,3 / 4)$ at the critical leverage equilibrium. For

\footnotetext{
21 Without deposit insurance, Gersbach et al. (2015) have already shown that non-optimalities can arise. We extend this proof to the case of deposit insurance.
} 
$R_{F} \approx \widehat{R}_{F}$, we obtain $y_{F} \approx y_{F}^{*}$ and $0<E \approx E^{*}$. If in addition, we set $\mu=0.99$ in $(11)$, then $\mathcal{D}_{\mu}(E)<100 \cdot\left[\left(\omega-y_{F}\right) \cdot(1-0.99 \underline{R} / \bar{R})\right] \leq(100 / 25) \cdot 0.208=$ $0.832<y_{F}$. This means that the entire insurance premium can be invested in riskfree technology when deposit insurance provides $99 \%$ coverage. It follows that the proof of Proposition 5 can be repeated with $99 \%$ deposit insurance coverage instead of actuarially fair deposit insurance. Hence it is possible to have equilibria where banks default in the bad state, there is $99 \%$ coverage by deposit insurance, government bail-out of banks is necessary, and the equilibrium allocation is non-optimal. The construction is independent of the probability $\sigma$, provided that $\sigma \in(0,1)$.

In this section, we have shown how financial intermediation cum deposit insurance can change the equilibrium allocation. While the optimal allocation is still supported by a continuum of equilibria, there is also a continuum of non-optimal allocations which can be supported by equilibria of this economy. Even in the presence of deposit insurance, the incentive of banks to maximize expected return on equity can result in over-investment in the risky technology, and under-investment in the safe technology, relative to what is optimal for the households. We have shown that non-optimal equilibrium allocations can persist even in the presence of a deposit insurance with a high cover ratio. Intuitively, this means that imposing a surcharge on the actuarially fair premium need not guarantee an optimal allocation, even if this surcharge is chosen very high.

\subsection{Too little investment in the risky sector?}

We have seen that there can be equilibria with actuarially fair deposit insurance and $y_{F}<\widehat{y}_{F}$. In such an equilibrium, there is under-investment in the risk-free technology and over-investment in the risky technology, which is in line with most of the literature and prima facie intuition. The question remains whether there can be equilibria with deposit insurance and $y_{F}>\widehat{y}_{F}$ so that the allocation is non-optimal because of too much investment in the risk-free sector and too little investment in the risky sector. We show in Proposition 8 in Appendix $\mathrm{C}$ that an equilibrium with 0-deposit insurance and $y_{F}>\widehat{y}_{F}$ is impossible. ${ }^{22}$

\subsection{Individual choice of debt and equity}

So far, we have assumed that the amounts of debt and equity are determined by the choices of the households, and are evenly distributed to all banks. In the corporate finance literature, one would typically think of the capital structure as being chosen by individual banks. In particular, an individual bank would first choose the amount of equity it issues, and then decide on the amount of deposits it accepts. Under such an alternative assumption, all equilibria of our model could be replicated if we assume that households choose banks randomly to deposit their funds. ${ }^{23}$

\footnotetext{
22 The examination of cases with $\delta$-deposit insurance $(\delta>0)$ is left to future research.

23 This argument follows the logic developed in Gersbach et al. (2015).
} 
Alternatively, one could take a static rather than sequential corporate finance perspective and investigate whether the equilibria discussed in the present section persist if an individual bank deviates from the equilibrium debt-equity ratio, by changing simultaneously its choices of debt and equity. If an individual bank had an incentive to do so, then the entire continuum of banks would have the same incentive and the equilibrium would break down. However, both optimal and non-optimal equilibria would still arise in this case as well. For instance, if a bank selects a higher debt-equity ratio in order to achieve higher return on equity the market price of this amount of equity would increase accordingly, neutralizing any possible gains for shareholders at this deviating bank. ${ }^{24}$

\section{Deposit insurance with reinsurance}

\subsection{The reinsurance scheme}

In the previous section, we have seen that in the presence of a deposit insurance, it is still possible to support equilibria with default and with a non-optimal allocation of input to the two sectors. Non-optimal equilibria can exist not only when deposit insurance is actuarially fair but even when a premium above the actuarially fair level is charged, as with "systemic risk surcharges." In the present section, we introduce a deposit insurance with reinsurance, and we show that under that deposit insurance scheme, all equilibria of the model economy support the optimal allocation, even if they may involve bank default.

A deposit insurance with reinsurance works as follows: Banks pay a share $\delta$ of their deposits to a deposit insurance fund as a premium. The deposit insurance fund writes reinsurance contracts with households: A household which is willing to pay an amount $q$ to the deposit insurance fund if the bad state occurs at $t=2$, receives a payment of one from the deposit insurance at time $t=1$. In equilibrium, the amount $q$ adjusts to clear the market for reinsurance contracts. Thus, the deposit insurance fund collects a total amount of $\delta D$ from the banks as a premium, passes all these funds on to households under a reinsurance contract, and the households have a payment obligation of $\delta D q$ in the bad state. We emphasize that household insolvency is not an issue here. In equilibrium, it is ensured that households have sufficient resources to meet their payment obligations under the reinsurance contracts. ${ }^{25}$

In this section, we define a reinsurance equilibrium. This equilibrium concept is based on the previously defined equilibrium with banks and $\delta$-deposit insurance, but is adapted to the economy in which the deposit insurance fund contracts reinsurance instead of investing in the risk-free technology. Our claim is that, for a suitable choice of $\delta$, all reinsurance equilibria support the optimal allocation. More precisely, we claim

\footnotetext{
24 This follows from non-arbitrage reasoning as otherwise households would only demand equity from the deviating bank, which would preclude market clearing.

25 All that we are implicitly assuming away is the possibility of strategic default by households. In practice, one way to exclude strategic default could be to treat households' payment obligations towards the deposit insurance fund like tax liabilities.
} 
that optimality is achieved if the deposit insurance premium is determined as follows:

$$
\delta_{R I E}\left(\psi, y_{F}\right)= \begin{cases}0 & \text { if } \psi f^{\prime}\left(y_{F}\right) \leq(1+\psi) \underline{R} \\ 1 / \psi & \text { if } \psi f^{\prime}\left(y_{F}\right)>(1+\psi) \underline{R} .\end{cases}
$$

We note that the deposit insurance premium $\delta$ depends on the capital structure and hence we have a flexible deposit premium and thus a flexible deposit insurance scheme. ${ }^{26}$ We discuss the two cases in turn. In the first case, the amount of deposits in the economy is sufficiently low so that banks will not default in the bad state. Hence, we have trivial deposit insurance with zero premium which never leads to any payment obligation. It is intuitive that the same logic as in Theorem 5 in the Appendix applies: The equilibrium without financial intermediation can be replicated.

The interesting case is where the amount of deposits in the economy is sufficiently large so that banks do default in the bad state. In that case, the deposit insurance receives premium payments $\delta D=(1 / \psi) D=E$. That is, every unit of equity is balanced by one reinsurance contract. Next, we consider the portfolio choice problem of the household in the presence of deposit insurance with reinsurance and bank default in the bad state:

$$
\begin{aligned}
\max _{\eta \in[0, \omega / E], \kappa \in \mathbb{R}_{+}} & \left(\frac{\sigma}{1-\theta}\right)\left(\eta E \bar{R}_{E}+(\omega+\kappa E-\eta E) R_{F}+\Pi_{F}\right)^{1-\theta} \\
& +\left(\frac{1-\sigma}{1-\theta}\right)\left((\omega+\kappa E-\eta E) R_{F}+\Pi_{F}-\kappa E q\right)^{1-\theta} .
\end{aligned}
$$

Recall how a reinsurance contract works: A household receives a payment of one at time $t=1$ and has to pay an amount $q$ at time $t=2$ if and only if the bad state occurs. If a household enters into $\kappa E$ such reinsurance contracts, this yields a loss of $\kappa E q$ in the bad state.

The above portfolio choice problem is best understood when compared to the analogous problem in the previous section: As before, we use $E$ to denote the average equity investment of households. Whatever an individual household's choice of equity investment may be, it can be expressed as a product $\eta E$ for some $\eta \in[0, \omega / E]$, and the factor $\eta$ can be taken as the individual household's choice variable. Contrary to the previous section, the deposit insurance does not lead to a restitution $t_{g}$ nor to a loss $t_{b}$ for all households-participation in the reinsurance contract is a decision of the individual household. Hence, there is a second choice variable $\kappa$. While the "average" household receives $\delta D=(1 / \psi) D=E$ in the first period under the reinsurance contract, the individual household receives $\kappa E$. The amount which the individual household can invest in equity or in risk-free assets is thus $\omega+\kappa E$ rather than just $\omega$. In the bad state, however, the household is obliged to pay $\kappa E q$. The profit $\Pi_{F}$ remains a fixed effect which is paid to every household in both states, regardless of the household's individual choices. Now let us consider the first-order conditions emanating from the

\footnotetext{
26 One can show that no flexible deposit insurance scheme can avoid equilibria with a bail-out if reinsurance is absent. However, flexible deposit insurance might nevertheless yield socially optimal solutions which will be addressed in our subsequent research.
} 
above portfolio problem:

$$
\begin{aligned}
& \left(\frac{\eta E \bar{R}_{E}+(\omega+\kappa E-\eta E) R_{F}+\Pi_{F}}{(\omega+\kappa E-\eta E) R_{F}+\Pi_{F}-\kappa E q}\right)^{\theta}=\left(\frac{\sigma}{1-\sigma}\right)\left(\frac{\bar{R}_{E}-R_{F}}{R_{F}}\right), \\
& \left(\frac{\eta E \bar{R}_{E}+(\omega+\kappa E-\eta E) R_{F}+\Pi_{F}}{(\omega+\kappa E-\eta E) R_{F}+\Pi_{F}-\kappa E q}\right)^{\theta}=\left(\frac{\sigma}{1-\sigma}\right)\left(\frac{R_{F}}{q-R_{F}}\right)
\end{aligned}
$$

These portfolio conditions admit multiple optimal portfolios for an individual household. The model economy includes two states, so two independent assets suffice for market completeness. The reinsurance contract is therefore a redundant asset. As a result, the individual household is indifferent between a continuum of possible portfolio choices. All these portfolio choices, however, lead to the same consumption bundle. Let us now turn to that consumption bundle by considering the aggregate consumption demanded by all households. In the good state, we find

$$
\begin{aligned}
c_{g} & =E \bar{R}_{E}+\omega R_{F}+\Pi_{F} \\
& =((1-\delta) D+E) \bar{R}-D R_{F}+\omega R_{F}+f\left(y_{F}\right)-y_{F} R_{F} \\
& =D \bar{R}+f\left(y_{F}\right)+R_{F}\left(y_{M}-D\right) \\
& =y_{M} \bar{R}+f\left(y_{F}\right) .
\end{aligned}
$$

In order to understand this chain of equalities, we need the following considerations: Banks can choose how to invest an amount $(1-\delta) D+E$, and as by Proposition 1 , they invest this entire amount in the risky technology. Since only the banks can invest in the risky technology, this implies $(1-\delta) D+E=y_{M}$. Moreover, since $\delta=1 / \psi=E / D$, we have $y_{M}=D$. Finally, the above chain of equalities uses the market-clearing conditions for the investment good so that $y_{M}=\omega-y_{F}$. Using the same considerations, we can also show that

$$
c_{b}=y_{M} \underline{R}+f\left(y_{F}\right) .
$$

Analogously to the previous section, the market-clearing condition for the investment good combined with appropriate definitions of return on equity and of $q$ implies market-clearing for the consumption good in both states. This observation allows us to rewrite Eqs. (29) and (30) above as

$$
\begin{aligned}
& \left(\frac{c_{g}}{c_{b}}\right)^{\theta}=\left(\frac{\sigma}{1-\sigma}\right)\left(\frac{\bar{R}_{E}-R_{F}}{R_{F}}\right), \\
& \left(\frac{c_{g}}{c_{b}}\right)^{\theta}=\left(\frac{\sigma}{1-\sigma}\right)\left(\frac{R_{F}}{q-R_{F}}\right) .
\end{aligned}
$$


These two equations imply that

$$
\left(\frac{\bar{R}_{E}-R_{F}}{R_{F}}\right)=\left(\frac{R_{F}}{q-R_{F}}\right) .
$$

This expression can be rewritten as

$$
\left(\frac{\bar{R}_{E}}{R_{F}}\right)=\left(\frac{R_{F}}{q-R_{F}}\right)+1,
$$

or, equivalently,

$$
\left(\frac{\bar{R}_{E}}{R_{F}}\right)=\left(\frac{q}{q-R_{F}}\right) .
$$

Finally, multiplying by $R_{F}$ and dividing by $q$ reveals that

$$
\left(\frac{\bar{R}_{E}}{q}\right)=\left(\frac{R_{F}}{q-R_{F}}\right) .
$$

We see that the three ratios $\left(\frac{\bar{R}_{E}}{q}\right)$ and $\left(\frac{R_{F}}{q-R_{F}}\right)$ as well as $\left(\frac{\bar{R}_{E}-R_{F}}{R_{F}}\right)$ are all equal. In particular, this gives us the condition

$$
\left(\frac{c_{g}}{c_{b}}\right)^{\theta}=\left(\frac{\sigma}{1-\sigma}\right)\left(\frac{\bar{R}_{E}}{q}\right) .
$$

Intuitively, the condition says that a household cannot benefit from reallocation an infinitesimal amount of its investment between bank equity and reinsurance contracts.

We are now ready for the statement of the equilibrium definition.

\subsection{Reinsurance equilibrium}

Definition 3 A reinsurance equilibrium is a tuple $\left(c_{g}^{*}, c_{b}^{*}, y_{M}^{*}, y_{F}^{*}, E^{*}, \psi^{*}, \bar{R}_{E}^{*}, \underline{R}_{E}^{*}\right.$, $\left.R_{F}^{*}, q^{*}, \delta^{*}\right)$ which solves the following system of equations:

$$
\begin{aligned}
\left(\frac{c_{g}}{c_{b}}\right)^{\theta} & =\left(\frac{\sigma}{1-\sigma}\right)\left(\frac{\bar{R}_{E}-R_{F}}{R_{F}-\underline{R}_{E}}\right), \\
c_{g} & =f\left(y_{F}\right)+y_{M} \bar{R}, \\
c_{b} & =f\left(y_{F}\right)+y_{M} \underline{R},
\end{aligned}
$$




$$
\begin{aligned}
y_{F} & =\omega-y_{M}, \\
y_{M} & =(1+\psi-\delta \psi) E, \\
\bar{R}_{E} & =(1+\psi-\delta \psi) \bar{R}-\psi R_{F}, \\
\underline{R}_{E} & =\max \left\{0,(1+\psi-\delta \psi) \underline{R}-\psi R_{F}\right\}, \\
R_{F} & =f^{\prime}\left(y_{F}\right), \\
\delta \psi q & =-\min \left\{0,(1+\psi-\delta \psi) \underline{R}-\psi R_{F}\right\}, \\
\delta & =\delta_{R I E}\left(\psi, y_{F}\right),
\end{aligned}
$$

as well as the additional restriction

$$
\left(\frac{c_{g}}{c_{b}}\right)^{\theta}=\left(\frac{\sigma}{1-\sigma}\right)\left(\frac{\bar{R}_{E}}{q}\right)
$$

in case $\delta \psi q>0$, and moreover, satisfies the inequalities $R_{F}^{*}<\sigma \bar{R}+(1-\sigma) \underline{R}$ and $E(1+\psi) \leq \omega$.

Equations (31) through (38) correspond to the equations in Definition 1 of the equilibrium with banks and $\delta$-deposit insurance. Equation (39) simply says that the payment obligation of households under the reinsurance contract corresponds exactly to the amount of the shortfall in the bad state. Equation (40) reiterates the above construction of the deposit insurance premium. Finally, Eq. (41) only becomes relevant if a shortfall does occur in the bad state, and a non-zero deposit insurance is concluded. In that case, the portfolio decision of the household is no longer one-dimensional. Instead, the household can be thought of as choosing two portfolio variables. As before, in equilibrium, the household should have no incentive to move an infinitesimal amount of its investment from bank equity to bank deposits (or to risk-free technology investment). This requirement is already formalized in Eq. (31) above. In addition, the household should not have an incentive to contract an infinitesimal extra amount of reinsurance and invest the proceeds at time $t=1$ into bank equity. This requirement is represented by Eq. (41).

Also in the presence of reinsurance, the cost of bank defaults is ultimately borne by the households. Instead of paying a lump-sum tax to finance a government bail-out, they have payment obligations under the reinsurance contract. It may seem that the two scenarios are quite similar after all, and one may wonder why they have different consequences for allocative optimality. In order to understand this, recall that each individual household remains completely free to enter into a reinsurance contract, while the lump-sum tax is obviously mandatory for all households, irrespective of their individual investment decision. In equilibrium, the payment obligation $q$ adjusts to clear the market for reinsurance contracts. The benefit of this system is that individual households find it optimal to choose a portfolio which internalizes the risk associated with their investment in bank deposits. In contrast, without reinsurance, an individual household externalizes that risk to the deposit insurance fund and, ultimately, to other households. 
Another clarification is in order: Suppose that we are in an economy with banks, deposit insurance, and reinsurance as defined in the present section. We want to argue that the only "reasonable" equilibrium concept for such an economy is reinsurance equilibrium as in Definition 3. In order to see this, consider the following requirements: Any appropriate notion of equilibrium would be such that markets for consumption and investment goods clear, so Eqs. (32)-(33) should be part of any equilibrium definition. We have shown in Lemma 1 that banks want to invest fully in the risky technology, thus Eq. (35) would also have to hold in any equilibrium. Moreover, a reasonable equilibrium definition would also require that households do arbitrage between bonds in risk-free technology and risk-free deposits. Thus, the rate of return on deposits would have to be $R_{F}$ and, consequently, Eqs. (36)-(37) would hold. Recall also that Eq. (38) follows from firms' profit maximization, which would also be true in any equilibrium. Finally, households' portfolio choice would have to be optimal in any equilibrium as well, which means that Eq. (31) and, if pertinent, Eq. (41) have to hold. Thus, in the economy with banks, deposit insurance, and reinsurance, there is no loss in focusing on the notion of reinsurance equilibrium.

\subsection{Optimality of the reinsurance equilibrium}

Theorem 3 below is the main result of the present paper. It claims that in an economy where the deposit insurance fund contracts reinsurance rather than invest in risk-free assets, non-optimal allocations can no longer be consistent with equilibrium.

Theorem 3 All reinsurance equilibria support the optimal allocation.

The proof of Theorem 3 is given in Appendix B. The existence of a reinsurance equilibrium can be shown by a similar construction as the existence of an equilibrium with banks and $\delta$-deposit insurance which supports the optimal allocation. Moreover, a reinsurance equilibrium with default also exists, but it is unique. That is, only one debt-equity ratio $\psi$ is consistent with such an equilibrium.

Corollary 1 All reinsurance equilibria with default (if any) involve the same debtequity ratio.

The proof of Corollary 1 is given in Appendix B. Alternatively, the uniqueness result can also be derived from the uniqueness of the Arrow-Debreu price system of the form $\left(1, \widehat{p}_{g}, \widehat{p}_{b}\right)$. In the equilibrium with default, one unit of equity provides $\bar{R}_{E}^{*}=\psi \cdot\left(\bar{R}-R_{F}\right)$ units of consumption in the good state and nothing in the bad state. The reinsurance contract delivers $q$ units of consumption in the bad state, where $E q=\Lambda=D \cdot\left(R_{F}-\underline{R}\right)$, hence $q=\psi \cdot\left(R_{F}-\underline{R}\right)$. But then $1 / \widehat{p}_{g}=\bar{R}_{E}^{*}$ and $1 / \widehat{p}_{b}=q$. Each of these two equations fixes $\psi$. 
As a next step, we show constructively that a reinsurance equilibrium with default exists. Let a tuple $\left(c_{g}^{\star}, c_{b}^{\star}, y_{M}^{\star}, y_{F}^{\star}, E^{\star}, \psi^{\star}, \bar{R}_{E}^{\star}, \underline{R}_{E}^{\star}, q^{\star}, \delta^{\star}\right)$ be defined as follows:

$$
\begin{aligned}
\psi^{\star} & =\frac{\widehat{R}_{F}}{\widehat{R}_{F}-\underline{R}}+\frac{\widehat{R}_{F}}{\bar{R}-\widehat{R}_{F}}, \\
y_{F}^{\star} & =\widehat{y}_{F}, \\
y_{M}^{\star} & =\widehat{y}_{M}, \\
\bar{R}_{E}^{\star} & =\psi^{\star}\left(\bar{R}-R_{F}^{\star}\right), \\
\underline{R}_{E}^{\star} & =0, \\
q^{\star} & =\psi^{\star}\left(R_{F}^{\star}-\underline{R}\right), \\
E^{\star} & =y_{M}^{\star} / \psi^{\star}, \\
\delta^{\star} & =1 / \psi^{\star} .
\end{aligned}
$$

Proposition 6 The tuple $\left(c_{g}^{\star}, c_{b}^{\star}, y_{M}^{\star}, y_{F}^{\star}, E^{\star}, \psi^{\star}, \vec{R}_{E}^{\star}, \underline{R}_{E}^{\star}, q^{\star}, \delta^{\star}\right)$ is a reinsurance equilibrium.

The proof of Proposition 6 is given in Appendix B. This yields:

\section{Theorem 4 A reinsurance equilibrium with default exists.}

To sum up, we have established the following findings:

First, all reinsurance equilibria involve the optimal allocation, even if banks default. The reason is that neither in the good nor in the bad state, portfolio decisions of households are impacted by transfers from governments-refunds from the deposit insurance fund or taxes to bail out banks. Hence, the banking system receives the socially optimal aggregate amount of investment goods to be invested in the risky sector in the form of deposits and equity and the banking system cannot increase the scale further.

Second, while a continuum of possible capital structures and associated non-optimal equilibria with default deposit insurance exists, only one equilibrium capital structure under reinsurance exists in which banks default. The reason is as follows. Since all reinsurance equilibria involve the optimal allocation, the amount of risky assets for households is equal to the amount in the Arrow-Debreu world. A particular amount of bank equity contracts and thus a particular capital structure requires a particular combination of deposit insurance and reinsurance contracts to avoid government bailout. Only for one particular capital structure will the ensuing portfolio of risky assets (bank equity and reinsurance contracts) mimic the amount of risky assets in the ArrowDebreu setting. Thus, the equilibrium capital structure in the reinsurance equilibrium with default is unique.

Third, we have assumed that households honor their obligations when they (freely) choose to acquire reinsurance contracts. One might be concerned about strategic default of households in this context. Such concerns are important and might require some wealth or collateral thresholds for households to qualify for the acquisition of reinsurance contracts. 
Fourth, one may wonder how our main results would carry over to a model with an arbitrary (finite) number of states of nature. Indeed, the existence of non-optimal equilibrium allocations requires only that there is (at least) one state in which the cover ratio of the deposit insurance is strictly less than one. Suppose that there are $n$ states of nature, and the cover ratio of the deposit insurance fund is strictly less than one in $m<n$ of those states. Then, we can guarantee that the optimal allocation obtains in any equilibrium by allowing for a set of $m$ independent reinsurance contracts.

\section{Conclusion and extensions}

We have performed a simple general equilibrium analysis of deposit insurance and have derived two main results: First, deposit insurance in itself does not guarantee optimal equilibrium allocations, not even with very high premia. Second, deposit insurance cum reinsurance does guarantee that the optimal allocation is achieved in equilibrium.

It is useful to stress that the main logic behind both of these results would apply in many other general equilibrium models with banks. Deposit insurance alone cannot prevent portfolio decisions of households that cause distortions regarding the socially optimal mix of risky and safe assets. The reason is that deposit insurance either leads to taxation in bad states to cover bail-out costs or to additional transfers in good states since the insurance fund was not needed.

A judicious combination of deposit insurance and reinsurance avoids both taxation and transfers from the government since the amount of reinsurance contracts is linked to the capital structures of banks (and deposit insurance scheme). This, in turn, pins down the equilibrium capital structure of banks. This logic could be applied to any other general equilibrium model with banks and aggregate risk.

The model allows some important extensions. One could, for instance, introduce costs of monitoring or moral hazard at the level of bank managers. In the former case, the analysis carries over readily to economies in which monitoring is costly and costs per loan are constant. In the latter case, in the spirit of Holmström and Tirole (1997), the bank manager must receive an incentive pay that motivates him to monitor firms. Then, one can only achieve a second-best allocation. Given the second-best allocation, one can perform the parallel exercise and a judicious combination of deposit insurance and reinsurance implements the second-best allocation. ${ }^{27}$

Of course, numerous other extensions deserve further scrutiny. For instance, the reinsurance scheme can be viewed as a form of catastrophe bond. Since the risk of banking crises is notoriously difficult to assess, reinsurance of deposit insurance might need professional expertise. One might thus ask whether the same role for reinsurance as in our main theorem could be performed by reinsurance companies

\footnotetext{
27 Suppose, e.g., that shareholders need to pay by $(0<b<1)$ to bankers in order to ensure monitoring of loans ( Holmström and Tirole (1997)) or to avoid diversion of funds. Then, we can repeat the entire exercise with revised returns $\bar{R}-b, \underline{R}-b$ on investments in $y_{M}$ for financiers of banks and income $b y_{M}$ of bank managers. The allocation is at most second-best, since lower returns will attract too little funds to the risky sector. However, given bankers' incentive constraints, the allocation is second-best, indeed. More formal details are available upon request.
} 
which households finance by equity contracts. One might also consider circumstances when there is ambiguity about the occurrence of banking crises and how reinsurance has to be designed in such circumstances. Finally, how insurance schemes have to be designed when banking competition is imperfect is another important avenue of research, following the comprehensive framework outlined in Vives (2016). These extensions will further enrich the socially valuable dual role that deposit insurance and reinsurance can have in insuring the financial system.

Funding Open Access funding provided by ETH Zurich. No third-party funding was received for this project.

\section{Declarations}

\section{Conflict of interest None.}

Open Access This article is licensed under a Creative Commons Attribution 4.0 International License, which permits use, sharing, adaptation, distribution and reproduction in any medium or format, as long as you give appropriate credit to the original author(s) and the source, provide a link to the Creative Commons licence, and indicate if changes were made. The images or other third party material in this article are included in the article's Creative Commons licence, unless indicated otherwise in a credit line to the material. If material is not included in the article's Creative Commons licence and your intended use is not permitted by statutory regulation or exceeds the permitted use, you will need to obtain permission directly from the copyright holder. To view a copy of this licence, visit http://creativecommons.org/licenses/by/4.0/.

\section{Appendix A: Equilibria without Financial Intermediation}

An equilibrium in this economy is defined as follows:

Definition 4 An equilibrium without financial intermediation is a tuple $\left(p_{g}^{*}, p_{b}^{*}, c_{g}^{*}, c_{b}^{*}\right.$, $\left.y_{F}^{*}, y_{M}^{*}, \Pi_{F}^{*}\right) \gg 0^{28}$ which satisfies the following system of equations:

$$
\begin{aligned}
\left(\frac{c_{g}}{c_{b}}\right)^{\theta} & =\left(\frac{p_{b}}{p_{g}}\right)\left(\frac{\sigma}{1-\sigma}\right), \\
\omega & =p_{g} c_{g}+p_{b} c_{b}-\Pi_{F}, \\
\Pi_{F} & =\left(p_{g}+p_{b}\right) f\left(y_{F}\right)-y_{F}, \\
f^{\prime}\left(y_{F}\right) & =\left(p_{g}+p_{b}\right)^{-1}, \\
y_{M} & =\omega-y_{F}, \\
c_{g} & =f\left(y_{F}\right)+y_{M} \bar{R}, \\
c_{b} & =f\left(y_{F}\right)+y_{M} \underline{R} .
\end{aligned}
$$

The first equation is the optimal ratio of consumptions in both states for the household and thus represents the maximization of expected household utility. The second

\footnotetext{
28 Throughout the paper we use the vector notation $v_{1} \gg v_{2}$ if vector $v_{1}$ is strictly greater in all components than vector $v_{2}$, and $v_{1}>v_{2}$ if $v_{1}$ is weakly greater in all components than $v_{2}$ with at least one strict inequality.
} 
equation is the household's budget constraint, taking into account that the profits of risk-free technology firms are distributed to households, while risky technology firms make zero profits. The third equation specifies the risk-free technology profits, and the fourth equation is the condition for optimal producer choice. The remaining equations are standard market-clearing conditions for investment good, consumption good in the good state, and consumption good in the bad state, respectively.

Substitute the expressions for $c_{g}^{*}, c_{b}^{*}$, and $\Pi_{F}^{*}$ into the budget constraint to find

$$
\omega=y_{F}^{*}+y_{M}^{*} \cdot\left(p_{g} \bar{R}+p_{b} \underline{R}\right) .
$$

Using the fact that $\omega=y_{F}^{*}+y_{M}^{*}$, we see that the condition

$$
p_{g} \bar{R}+p_{b} \underline{R}=1
$$

emanating from optimal producer choice is implied by the system of equations in the definition of an equilibrium without financial intermediation.

\section{The equilibrium allocation}

\section{A first welfare theorem}

In this subsection, we characterize the optimal allocation of the investment good to the two sectors of production. We mean by an optimal allocation an allocation that maximizes household utility. Because of the CRRA utility function, the optimal allocation does not coincide with the productively efficient allocation which maximizes total expected output in the economy. More formally, we give the following definition of the optimal allocation.

Definition 5 The input allocation $\left(\widehat{y}_{F}, \omega-\widehat{y}_{F}\right)$ is optimal if it maximizes the household's utility

$$
\left(\frac{\sigma}{1-\theta}\right)\left(f\left(y_{F}\right)+\left(\omega-y_{F}\right) \bar{R}\right)^{1-\theta}+\left(\frac{1-\sigma}{1-\theta}\right)\left(f\left(y_{F}\right)+\left(\omega-y_{F}\right) \underline{R}\right)^{1-\theta}
$$

over $y_{F} \in[0, \omega]$.

The economy without financial intermediation was previously introduced in Gersbach et al. (2015). It has been shown that the optimal allocation exists, is unique, and allocates strictly positive amounts of the investment good to both sectors. Moreover, the concomitant Arrow-Debreu equilibrium is unique up to price normalization. For later reference, we denote the Arrow-Debreu equilibrium values by $\widehat{p}_{g}, \widehat{p}_{b}, \widehat{c}_{g}, \widehat{c}_{b}$, $\widehat{y}_{F}, \widehat{y}_{M}$ and $\widehat{\Pi}_{F}$. 
Examination of the first-order condition emanating from the optimization problem in the above definition reveals that the optimal allocation $\widehat{y}_{F}$ satisfies

$$
\left(\frac{\sigma}{1-\sigma}\right)\left(\frac{\bar{R}-f^{\prime}\left(\widehat{y}_{F}\right)}{f^{\prime}\left(\widehat{y}_{F}\right)-\underline{R}}\right)=\left(\frac{f\left(\widehat{y}_{F}\right)+\left(\omega-\widehat{y}_{F}\right) \bar{R}}{f\left(\widehat{y}_{F}\right)+\left(\omega-\widehat{y}_{F}\right) \underline{R}}\right)^{\theta} .
$$

The following proposition is the manifestation of the first welfare theorem in the model at hand.

Proposition 7 An equilibrium without financial intermediation involves the optimal allocation.

Proof In an equilibrium without financial intermediation, the market-clearing conditions imply that the right-hand side of Eq. (49) is equal to $\left(c_{g} / c_{b}\right)^{\theta}$. Moreover, in such an equilibrium, the conditions for optimal producer choice imply that

$$
p_{g} \bar{R}+p_{b} \underline{R}=\left(p_{g}+p_{b}\right) f^{\prime}\left(\widehat{y}_{F}\right)=1 \text {. }
$$

We can use this expression to show that

$$
\left(\frac{\bar{R}-f^{\prime}\left(\widehat{y}_{F}\right)}{f^{\prime}\left(\widehat{y}_{F}\right)-\underline{R}}\right)=p_{b} / p_{g}
$$

We see that the first-order condition for the optimal allocation and the equilibrium condition for optimal consumer choice coincide.

From the first-order condition describing the optimal allocation and from the inequalities $\omega>\widehat{y}_{F}$ and $\bar{R}>\underline{R}$, it can be inferred from Eq. (49) that if $\left(\widehat{y}_{F}, \omega-\widehat{y}_{F}\right)$ is the optimal allocation, then

$$
f^{\prime}\left(\widehat{y}_{F}\right)<\sigma \bar{R}+(1-\sigma) \underline{R} .
$$

Due to the concave technology in risk-free technology, the marginal product in the risk-free technology sector is lower than the marginal product in the risky technology sector at the optimal allocation. Due to risk aversion, it is not optimal for households to equalize the marginal products in both sectors. Hence, as pointed out before, the optimal allocation is not the "productively efficient" allocation.

\section{Reformulation of equilibrium}

It will be useful to work with a reformulation of the equilibrium without financial intermediation that does not involve the prices $\left(p_{g}, p_{b}\right)$ anymore. In order to achieve this reformulation, we start by considering the optimization problem of an individual household, taking choices of all other households as given. The individual household's optimization problem is "one-dimensional": The household chooses a share $\beta \in[0,1]$ 
of its initial endowment to be invested in the risk-free asset (that is, in risk-free technology production), and the complementary share $1-\beta$ to be invested in the risky asset (that is, risky technology production). Since the individual household has zero mass, it takes the allocation $y_{F}$ and the concomitant marginal product $f^{\prime}\left(y_{F}\right)$ as given. This is in contrast to the previous subsection where we considered the optimization of the entire allocation in the economy. We can express the individual household utility as a function of $\beta$ :

$$
U(\beta)=\left(\frac{\sigma}{1-\theta}\right)\left(c_{g}^{1-\theta}(\beta)\right)+\left(\frac{1-\sigma}{1-\theta}\right)\left(c_{b}^{1-\theta}(\beta)\right),
$$

which leads us to the first-order condition

$$
\left(\frac{c_{g}}{c_{b}}\right)^{\theta}=-\left(\frac{\sigma}{1-\sigma}\right)\left(\frac{\partial c_{g} / \partial \beta}{\partial c_{b} / \partial \beta}\right) .
$$

Equation (50) gives a general first-order condition for a one-dimensional consumer choice problem which will repeatedly be useful in the sequel. In the case at hand,

$$
\begin{aligned}
& c_{g}(\beta)=\beta\left(\omega+\Pi_{F}\right) f^{\prime}\left(y_{F}\right)+(1-\beta)\left(\omega+\Pi_{F}\right) \bar{R}, \\
& c_{b}(\beta)=\beta\left(\omega+\Pi_{F}\right) f^{\prime}\left(y_{F}\right)+(1-\beta)\left(\omega+\Pi_{F}\right) \underline{R},
\end{aligned}
$$

and thus Equation (50) becomes

$$
\left(\frac{c_{g}}{c_{b}}\right)^{\theta}=\left(\frac{\sigma}{1-\sigma}\right)\left(\frac{\bar{R}-f^{\prime}\left(y_{F}\right)}{f^{\prime}\left(y_{F}\right)-\underline{R}}\right) .
$$

Consider the following theorem.

Theorem 5 The tuple $\left(c_{g}^{*}, c_{b}^{*}, y_{F}^{*}, y_{M}^{*}\right) \gg 0$ is part of an equilibrium without financial intermediation if it solves the following system of equations:

$$
\begin{aligned}
y_{M} & =\omega-y_{F}, \\
c_{g} & =f\left(y_{F}\right)+y_{M} \bar{R}, \\
c_{b} & =f\left(y_{F}\right)+y_{M} \underline{R}, \\
\left(\frac{c_{g}}{c_{b}}\right)^{\theta} & =\left(\frac{\sigma}{1-\sigma}\right)\left(\frac{\bar{R}-f^{\prime}\left(y_{F}\right)}{f^{\prime}\left(y_{F}\right)-\underline{R}}\right) .
\end{aligned}
$$

Proof In order to prove the theorem, we need to show that for any tuple $\left(c_{g}^{*}, c_{b}^{*}, y_{F}^{*}, y_{M}^{*}\right)$ $\gg 0$ which satisfies Eqs. (51)-(54), one can find prices $\left(p_{g}^{*}, p_{b}^{*}\right)$ such that $\left(c_{g}^{*}, c_{b}^{*}, y_{F}^{*}, y_{M}^{*}, p_{g}^{*}, p_{b}^{*}\right)$ is an equilibrium without financial intermediation. Indeed, let prices $\left(p_{g}^{*}, p_{b}^{*}\right)$ be given by the equalities

$$
p_{b}^{*} / p_{g}^{*}=\frac{\bar{R}-f^{\prime}\left(y_{F}^{*}\right)}{f^{\prime}\left(y_{F}^{*}\right)-\underline{R}}
$$


and

$$
\left(p_{g}^{*}+p_{b}^{*}\right)^{-1}=f^{\prime}\left(y_{F}^{*}\right)
$$

It is now easily verified that all the equations in the definition of an equilibrium without financial intermediation are satisfied.

\section{Appendix B: Proofs}

Proof of Lemma 1 Consider first the case where $\bar{\pi}(\alpha)>0=\underline{\pi}(\alpha)$. Then,

$$
\partial(\sigma \bar{\pi}(\alpha)+(1-\sigma) \underline{\pi}(\alpha)) / \partial \alpha=\sigma\left(\bar{R}-R_{F}\right)((1-\delta) D+E) .
$$

This partial derivative is independent of $\alpha$. The supposition $R_{F}<\sigma \bar{R}+(1-\sigma) \underline{R}$ implies that $\bar{R}-R_{F}>0$, and thus the above partial derivative is strictly positive, as desired. Now consider the case where $\bar{\pi}(\alpha)>\underline{\pi}(\alpha)>0$. Then, the relevant partial derivative is

$\partial(\sigma \bar{\Pi}(\alpha)+(1-\sigma) \underline{\pi}(\alpha)) / \partial \alpha=\sigma\left(\bar{R}-R_{F}\right)((1-\delta) D+E)+(1-\sigma)\left(\underline{R}-R_{F}\right)((1-\delta) D+E)$.

Again, invoking the supposition that $R_{F}<\sigma \bar{R}+(1-\sigma) \underline{R}$ shows that this partial derivative is strictly positive. Indeed, the optimization problem of the representative bank has no interior solution.

Proof of Proposition 1 We are going to show that all households choose the same equity, while the above representative household approach assumes this. More formally, an individual household's equity is equal to $\eta E$, where the individual household's choice variable is $\eta$, while $E$ is the aggregate level of equity chosen by all households. Hence, if some household chooses $\eta>1$, then it chooses to invest more in equity than the "average" household, while if $\eta<1$, then this particular household invests less than "average" in equity. It will be sufficient to consider the range $\eta \in[0, \omega / E]$. The portfolio choice problem of an individual household can now be stated formally as follows:

$$
\begin{aligned}
& \max _{\eta \in[0, \omega / E]}\left(\frac{\sigma}{1-\theta}\right)\left(\eta E \bar{R}_{E}+(\omega-\eta E) R_{F}+t_{g}+\Pi_{F}\right)^{1-\theta} \\
& +\left(\frac{1-\sigma}{1-\theta}\right)\left(\eta E \underline{R}_{E}+(\omega-\eta E) R_{F}+t_{b}+\Pi_{F}\right)^{1-\theta} .
\end{aligned}
$$

Recalling that $E>0$, the first-order condition for the consumer choice problem can be written as

$$
\left(\frac{\sigma}{1-\sigma}\right)\left(\frac{\bar{R}_{E}-R_{F}}{R_{F}-\underline{R}_{E}}\right)=\left(\frac{\eta E \bar{R}_{E}+(\omega-\eta E) R_{F}+t_{g}+\Pi_{F}}{\eta E \underline{R}_{E}+(\omega-\eta E) R_{F}+t_{b}+\Pi_{F}}\right)^{\theta} .
$$


The left-hand side is independent of $\eta$. For $\bar{R}_{E}>R_{F}>\underline{R}_{E}$, the right-hand side is strictly increasing in $\eta$. That is, only one value of $\eta \in[0, \omega / E]$ can solve this firstorder condition if the existence of one solution is guaranteed. Hence, all households must choose the same portfolio. But then it follows that $\eta=1$.

Proof of Proposition 2 (i) The proof is constructive. Let $\left(c_{g}^{*}, c_{b}^{*}, y_{M}^{*}, y_{F}^{*}\right)$ be the optimal input allocation and concomitant consumptions, and choose any $\psi^{*} \in\left[0, \frac{R}{R_{F}^{*}-\underline{R}}\right]$. Notice that any choice of $\psi^{*}$ in that interval guarantees that banks do not default in the bad state. Now define $E^{*}, \bar{R}_{E}^{*}$, and $\underline{R}_{E}^{*}$ as follows:

$$
\begin{aligned}
E^{*} & =\frac{y_{M}^{*}}{1+\psi^{*}}, \\
\bar{R}_{E}^{*} & =\left(1+\psi^{*}\right) \bar{R}-\psi^{*} R_{F}^{*}, \\
\underline{R}_{E}^{*} & =\left(1+\psi^{*}\right) \underline{R}-\psi^{*} R_{F}^{*} .
\end{aligned}
$$

We need to check that the tuple $\left(c_{g}^{*}, c_{b}^{*}, y_{M}^{*}, y_{F}^{*}, \psi^{*}, E^{*}, \bar{R}_{E}^{*}, \underline{R}_{E}^{*}\right)$ solves Eqs. (12) through (18) in the definition of the equilibrium with banks and $\delta$-deposit insurance. This is immediate for Eqs. (13) through (18). To see that it is also true for Eq. (12), we use Theorem 1(i) and observe that with 0 -deposit insurance,

$$
\frac{\bar{R}_{E}-R_{F}}{R_{F}-\underline{R}_{E}}=\frac{(1+\psi) \bar{R}-(1+\psi) R_{F}}{(1+\psi) R_{F}-(1+\psi) \underline{R}}=\frac{\bar{R}-R_{F}}{R_{F}-\underline{R}} .
$$

(ii) The proof is by contradiction. Again, let $\left(c_{g}^{*}, c_{b}^{*}, y_{M}^{*}, y_{F}^{*}\right)$ be the optimal input allocation and concomitant consumptions, and choose any $\psi^{*} \in\left[0, \frac{\underline{R}}{R_{F}^{*}-\underline{R}}\right]$. Notice that any choice of $\psi^{*}$ in that interval guarantees that banks do not default in the bad state. Now suppose that, for some $\delta>0$, there is an equilibrium with banks and $\delta$ deposit insurance that supports the optimal input allocation. Then, in order to conform to Definition 1, the return on equity in that equilibrium must be

$$
\begin{aligned}
& \bar{R}_{E}^{*}=\left(1+\psi^{*}-\delta \psi^{*}\right) \bar{R}-\psi^{*} R_{F}^{*}, \\
& \underline{R}_{E}^{*}=\left(1+\psi^{*}-\delta \psi^{*}\right) \underline{R}-\psi^{*} R_{F}^{*} .
\end{aligned}
$$

Then, we find

$$
\frac{\bar{R}_{E}-R_{F}}{R_{F}-\underline{R}_{E}}=\frac{(1+\psi)\left(\bar{R}-R_{F}\right)-\delta \psi \bar{R}}{(1+\psi)\left(R_{F}-\underline{R}\right)+\delta \psi \underline{R}} \neq \frac{\bar{R}-R_{F}}{R_{F}-\underline{R}} .
$$

The input allocation is not optimal according to Theorem 1(i), a contradiction.

Proof of Proposition 3 Suppose that $\delta<(1-\sigma)\left(\frac{\bar{R}-\underline{R}}{\bar{R}}\right)$. This inequality can be rewritten as

$$
\delta<\frac{\bar{R}-\sigma \bar{R}-(1-\sigma) \underline{R}}{\bar{R}} .
$$


Now consider the inequality $f^{\prime}\left(y_{F}^{\prime}\right)<\sigma \bar{R}+(1-\sigma) \underline{R}$. It can be written as

$$
-(1-\sigma) \underline{R}<\sigma \bar{R}-f^{\prime}\left(y_{F}^{\prime}\right) .
$$

Substituting for $-(1-\sigma) \underline{R}$ into the first inequality above yields

$$
\delta<\frac{\bar{R}-f^{\prime}\left(y_{F}^{\prime}\right)}{\bar{R}} \text {. }
$$

Now the proposition follows from Theorem 2.

Proof of Proposition 5 Take the critical leverage equilibrium introduced in Definition 2 where investment in risk-free technology is $y_{F}^{*}$, investment in the risky sector is $y_{M}^{*}=\omega-y_{F}^{*}$, deposits assume the threshold value $D^{*}=\frac{R}{R_{F}^{*}} y_{M}^{*}$, equity assumes the value $E^{*}=\left(1-\frac{\underline{R}}{R_{F}^{*}}\right) y_{M}^{*}$ and the equilibrium bond return $R_{F}^{*}$ satisfies $\sigma \bar{R}+$ $(1-\sigma) \underline{R}>R_{F}^{*}$. Let us fix a bond return (denoted by $\check{R}_{F}$ ) slightly above $R_{F}^{*}$ such that $\sigma \bar{R}+(1-\sigma) \underline{R}>\check{R}_{F}$ and the bank chooses $\alpha=1$. Given the higher bond return $\check{R}_{F}$, the representative risk-free technology firm chooses a profit maximizing input denoted by $\check{y}_{F}$, with $\check{y}_{F}<y_{F}^{*}$. The resulting profit is denoted by $\check{\Pi}_{F}$ and satisfies $\check{\Pi}_{F}<\Pi_{F}^{*}$.

At the critical leverage equilibrium, the demand for equity is $E^{*}$ when $t_{b}=0$ and $\delta=0$, the return on bonds is $R_{F}^{*}$ and a unit of equity pays $\bar{R}\left(1+\frac{D^{*}}{E^{*}}\right)-R_{F}^{*} \frac{D^{*}}{E^{*}}$ in the good state and zero in the bad state. If one replaced $R_{F}^{*}$ by $\check{R}_{F}>R_{F}^{*}, \Pi_{F}^{*}$ by $\check{\Pi}_{F}$, $\delta=0$ by the actuarially fair rate given by (9) when $\mu=1-\sigma, E=E^{*}$ and $D=D^{*}$, and $t_{b}=0$ by $\check{t}_{b}=-(1-\delta) \check{R}_{F} D^{*}+\underline{R}\left(E^{*}+(1-\delta) D^{*}\right)<0$, then the household would demand more of the risk-free asset. ${ }^{29}$

Now assume $E \in\left(0, E^{*}\right]$ and $D=\mathcal{D}_{1-\sigma}(E)$ given by (11). Consider the household's portfolio choice when the profit distributed is $\breve{\Pi}_{F}, \delta$ is given by (9) with $\mu=1-\sigma$, $t_{b}=-(1-\delta) \check{R}_{F} D+\underline{R}(E+(1-\delta) D)$, the return on bonds is $\check{R}_{F}$ and a unit of equity pays $\bar{R}\left(1+\frac{(1-\delta) D}{E}\right)-\check{R}_{F} \frac{D}{E}$ in the good state and zero in the bad state. There is a unique optimal $\gamma(E) \in[0,1]$ so that the household invests $\gamma(E) \omega$ in safe assets and $[1-\gamma(E)] \omega$ in equity. By Berge's maximum theorem (or the explicit solution of the household's portfolio choice problem), $\gamma(E)$ is a continuous function

29 Observe first of all that $c_{g}>c_{b}$ and homothetic preferences of the household (together with standard properties) imply that $|M R S|$ is smaller at the consumption bundle $\left(\check{c}_{g}, \check{c}_{b}\right)=\left(c_{g}-\left(\Pi_{F}-\check{\Pi}_{F}\right)+\right.$ $\left.\delta D^{*} \check{R}_{F}, c_{b}-\left(\Pi_{F}-\check{\Pi}_{F}\right)-\check{t}_{b}\right)$ than at $\left(c_{g}, c_{b}\right)$. Next consider normalized gradients of the form $(|M R S|, 1)$. Denote by $\nabla$ the household's normalized gradient at $\left(c_{g}, c_{b}\right)$ and by $\check{\nabla}$ its normalized gradient at $\left(\check{c}_{g}, \check{c}_{b}\right)$. If in the reference equilibrium situation, the household replaces one unit of the bond by one unit of equity, then consumption is changed in the direction $v=\left(\bar{R}\left(1+\frac{D^{*}}{E^{*}}\right)-R_{F} \frac{D^{*}}{E^{*}}-R_{F},-R_{F}\right)$ and at equilibrium, portfolio choice is optimal, that is $\nabla \cdot v=0$. If in the new situation, the household replaces one unit of the bond by one unit of equity, then consumption is changed in the direction $\check{v}=\left(\bar{R}\left(1+\frac{D^{*}}{E^{*}}\right)-\check{R}_{F} \frac{D^{*}}{E^{*}}-\check{R}_{f},-\check{R}_{F}\right)$. It follows that $0=\nabla \cdot v>\nabla \cdot \check{v}>\check{\nabla} \cdot \check{v}$. But $\check{\nabla} \cdot \check{v}<0$ means that the household benefits from reducing its equity holding and increasing its bond holding by the same amount. 
of $E$. Set $\eta(E)=[1-\gamma(E)] \omega$. As reasoned above, $\eta\left(E^{*}\right)<E^{*}$. Like in the proof of Proposition 6 of Gersbach et al. (2015), the examination of the solution of the household's portfolio choice problem shows existence of $E_{o} \in\left(0, E^{*}\right)$ with $\eta\left(E_{o}\right)>$ $E_{o}$. By the intermediate value theorem, there exists $E \in\left(E_{o}, E^{*}\right)$ with $\eta(E)=E$. At this $E$ and the corresponding values for $D, \delta$ and $t_{b}$, the asset market is cleared-as well as the consumption good market in both states-while the bond return is $\check{R}_{F}$ and risk-free technology production is less than at the Arrow-Debreu equilibrium. Hence the equilibrium allocation is non-optimal. By 3.5, bail-out is necessary if the bank defaults.

It remains to check whether the bank is actually going to default in the bad state. In the critical leverage equilibrium, $\underline{R}\left(E^{*}+D^{*}\right)-R_{F} D^{*}=0$. Let $\Delta=y_{F}^{*}-\check{y}_{F}>0$. Then $\underline{R}\left(E^{*}+D^{*}+\Delta\right)-\check{R}_{F}\left(D^{*}+\Delta\right)<0$. Further $E^{*}+D^{*}=\omega-y_{F}^{*}, E+D(1-\delta)=$ $\omega-\check{y}_{F}$ and $E<E^{*}$. Hence $E^{*}+D^{*}+\Delta=\omega-\check{y}_{F}=E+D(1-\delta)$ and $D^{*}+\Delta=\omega-E^{*}-y_{F}^{*}+y_{F}^{*}-\check{y}_{F}=\omega-E^{*}-\check{y}_{F}<\omega-E-\check{y}_{F}=(1-\delta) D<D$. It follows that $\underline{R}(E+(1-\delta) D)-\check{R}_{F} D<\underline{R}\left(E^{*}+D^{*}+\Delta\right)-\check{R}_{F}\left(D^{*}+\Delta\right)<0$, which means that the bank is going to default in the bad state, indeed.

Proof of Proposition 6 It is immediate that our construction satisfies Eqs. (34) through (40). Now consider Eq. (41). By substitution from the above construction of $c_{g}^{\star}, c_{b}^{\star}, \bar{R}_{E}^{\star}$ and $q^{\star}$, we can reduce Eq. (41) to

$$
\left(\frac{f\left(\widehat{y}_{F}\right)+\widehat{y}_{M} \bar{R}}{f\left(\widehat{y}_{F}\right)+\widehat{y}_{M} \underline{R}}\right)^{\theta}=\left(\frac{\sigma}{1-\sigma}\right)\left(\frac{\bar{R}-\widehat{R}_{F}}{\widehat{R}_{F}-\underline{R}}\right) .
$$

This equality is true due to the definition of $\widehat{y}_{F}$ and $\widehat{y}_{M}$. Indeed, our construction satisfies Eq. (41). Finally, we have to verify that our construction also satisfies Eqs. (31)-(33). Given the previous step, it is sufficient to show that the following equality is satisfied:

$$
\frac{\psi^{\star} \bar{R}-\left(1+\psi^{\star}\right) \widehat{R}_{F}}{\widehat{R}_{F}}=\frac{\bar{R}-\widehat{R}_{F}}{\widehat{R}_{F}-\underline{R}} .
$$

Solving this expression for $\psi^{\star}$, we see that it is simply equivalent to the definition of $\psi^{\star}$. Indeed, we have now shown that our construction satisfies all the Eqs. (31) through (41).

Proof of Theorem 2 Step 1. Fix $y_{F}^{\prime} \in Y_{F}^{\prime}$ and $\delta^{\prime}<\frac{\bar{R}-f^{\prime}\left(y_{F}^{\prime}\right)}{\bar{R}}$. Consider $\bar{R}_{E}$ as a function of $\psi$, thus

$$
\begin{aligned}
\bar{R}_{E}(\psi) & =\left(1+\psi-\delta^{\prime} \psi\right) \bar{R}-\psi f^{\prime}\left(y_{F}^{\prime}\right) \\
& =\bar{R}+\psi\left[\left(1-\delta^{\prime}\right) \bar{R}-f^{\prime}\left(y_{F}^{\prime}\right)\right] .
\end{aligned}
$$

Observe that the term in brackets is strictly positive, hence we find the limit behavior $\lim _{\psi \rightarrow 0} \bar{R}_{E}(\psi)=\bar{R}$ and $\lim _{\psi \rightarrow \infty} \bar{R}_{E}(\psi)=\infty$. Since $\bar{R}_{E}(\psi)$ is continuous on $\mathbb{R}_{+}$, we can invoke the intermediate value theorem to find that for any $\rho>\bar{R}$, there exists 
$\psi>0$ such that $\bar{R}_{E}(\psi)=\rho$.

Step 2. Now let us define the function

$$
\rho\left(y_{F}\right)=\left(\frac{f\left(y_{F}\right)+\left(\omega-y_{F}\right) \bar{R}}{f\left(y_{F}\right)+\left(\omega-y_{F}\right) \underline{R}}\right)^{\theta}\left(\frac{1-\sigma}{\sigma}\right) f^{\prime}\left(y_{F}\right)+f^{\prime}\left(y_{F}\right) .
$$

Observe that $\rho$ is continuous and strictly decreasing in $y_{F}$. Thus for $y_{F}^{\prime}$ we have $\rho^{\prime}:=\rho\left(y_{F}^{\prime}\right)>\rho\left(\widehat{y}_{F}\right) \geq \widehat{R}_{F} \cdot{ }^{30}$ We have now established that there is $\psi^{\prime}$ such that $\bar{R}_{E}\left(\psi^{\prime}\right)=\rho^{\prime}$.

Step 3. Consider the tuple $\left(c_{g}^{\prime}, c_{b}^{\prime}, y_{M}^{\prime}, y_{F}^{\prime}, E^{\prime}, \psi^{\prime}, \bar{R}_{E}^{\prime}, \underline{R}_{E}^{\prime}\right)$, where $y_{F}^{\prime}$ is as fixed in Step 1, $\psi^{\prime}$ is as defined in Step $2, \bar{R}_{E}^{\prime}=\bar{R}_{E}\left(\psi^{\prime}\right)$, and the remaining variables are given by:

$$
\begin{aligned}
y_{M}^{\prime} & =\omega-y_{F}^{\prime}, \\
E^{\prime} & =y_{M}^{\prime} /\left(1+\psi^{\prime}-\delta^{\prime} \psi^{\prime}\right), \\
c_{g}^{\prime} & =f\left(y_{F}^{\prime}\right)+y_{M}^{\prime} \bar{R}, \\
c_{b}^{\prime} & =f\left(y_{F}^{\prime}\right)+y_{M}^{\prime} \underline{R} .
\end{aligned}
$$

It is now easily verified that the tuple under consideration satisfies Eqs. (12)-(18). We note that $\underline{R}_{E}=0 .{ }^{31}$

Moreover, since (15) and (16) are satisfied, we note that even in the extreme case with households investing almost everything in deposits, $y_{F}^{\prime} \geq \delta D^{\prime}$ still holds.

Hence, the tuple constructed is indeed an equilibrium with banks and $\delta^{\prime}$-deposit insurance, as desired.

Proof of Theorem 3 Comparing the system of Eqs. (31)-(41) above with the system of Eqs. (51)-(54) describing the optimal allocation, we see that a reinsurance equilibrium

30 Regarding the latter inequality: By (20), the critical leverage equilibrium with 0-deposit insurance yields $\rho\left(\hat{y}_{F}\right)=\bar{R}_{E}^{*}$. By $(25)$ and $(27)$,

$$
\begin{aligned}
\bar{R}_{E}^{*} & =\frac{1}{f^{\prime}\left(\hat{y}_{F}\right)-\underline{R}} \cdot\left\{\left[\underline{R}-\underline{R}+f^{\prime}\left(\hat{y}_{F}\right)\right] \cdot \bar{R}-\underline{R} \cdot f^{\prime}\left(\hat{y}_{F}\right)\right\} \\
& =\frac{(\bar{R}-\underline{R}) \cdot f^{\prime}\left(\hat{y}_{F}\right)}{f^{\prime}\left(\hat{y}_{F}\right)-\underline{R}} \geq \bar{R}
\end{aligned}
$$

where the last inequality follows from $\bar{R}>f^{\prime}\left(\hat{y}_{F}\right)>\underline{R} \geq 0$. Hence $\rho\left(\hat{y}_{F}\right) \geq \bar{R}$. Actually, $>$ holds for $\underline{R}>0$ and $=$ holds for $\underline{R}=0$.

31 To see this, observe that $\underline{R}_{E}=0$ holds at the critical leverage equilibrium by definition: Banks are just at the brink of default. Any additional investment in the risky technology leads to default, and thus return on equity in the bad state remains zero. 
supports the optimal allocation if the equilibrium variables $\bar{R}_{E}^{*}$ and $y_{F}^{*}$ satisfy

$$
\frac{\bar{R}_{E}^{*}-R_{F}^{*}}{R_{F}^{*}-\underline{R}_{E}^{*}}=\frac{\bar{R}-R_{F}^{*}}{R_{F}^{*}-\underline{R}}
$$

In order to verify that this equality holds in any reinsurance equilibrium, we distinguish two cases. The first case is a reinsurance equilibrium in which $\psi^{*} R_{F}^{*} \leq\left(1+\psi^{*}\right) \underline{R}$. In such an equilibrium, $\delta^{*}=0$. Then, substituting for the returns on equity from Eqs. (36) and (37), we have

$$
\frac{\bar{R}_{E}^{*}-R_{F}^{*}}{R_{F}^{*}-\underline{R}_{E}^{*}}=\frac{\left(1+\psi^{*}\right) \bar{R}^{*}-\left(1+\psi^{*}\right) R_{F}^{*}}{\left(1+\psi^{*}\right) R_{F}^{*}-\left(1+\psi^{*}\right) \underline{R}}=\frac{\bar{R}-R_{F}^{*}}{R_{F}^{*}-\underline{R}},
$$

as desired. The second case is that of a reinsurance equilibrium in which $\psi^{*} R_{F}^{*}>$ $\left(1+\psi^{*}\right) \underline{R}$. In such an equilibrium, $\delta^{*}=1 / \psi^{*}$ and $\delta^{*} \psi^{*} q^{*}=q^{*}>0$. Thus, by applying Eq. (41) and by substitution for $\bar{R}_{E}^{*}$ and $q^{*}$ from Eqs. (36) and (39) and using $\underline{R}_{E}^{*}=0$, we obtain the chain of equalities

$$
\frac{\bar{R}_{E}^{*}-R_{F}^{*}}{R_{F}^{*}-\underline{R}_{E}^{*}}=\frac{\bar{R}_{E}^{*}-R_{F}^{*}}{R_{F}^{*}}=\frac{\bar{R}_{E}^{*}}{q}=\frac{\psi^{*} \bar{R}-\psi^{*} R_{F}^{*}}{\psi^{*} R_{F}^{*}-\psi^{*} \underline{R}}=\frac{\bar{R}-R_{F}^{*}}{R_{F}^{*}-\underline{R}} .
$$

(The first equality in the chain holds because banks default, in which case return on equity is zero.)

Indeed, all reinsurance equilibria support the optimal allocation.

Proof of Corollary 1 Consider a reinsurance equilibrium with default, and let $\bar{R}_{E}^{*}$ be the return on equity in the good state and $\psi^{*}$ be the debt-equity ratio in that equilibrium. From Theorem 3, it follows that

$$
\frac{\bar{R}_{E}^{*}-\widehat{R}_{F}}{\widehat{R}_{F}}=\frac{\bar{R}-\widehat{R}_{F}}{\widehat{R}_{F}-\underline{R}}
$$

Moreover, in a reinsurance equilibrium with default, Eq. (36) reduces to

$$
\bar{R}_{E}^{*}=\psi^{*}\left(\bar{R}-\widehat{R}_{F}\right)
$$

Substituting this expression for $\bar{R}_{E}^{*}$ in the previous equation, and suitably rearranging terms yields

$$
\psi^{*}=\frac{\widehat{R}_{F}}{\widehat{R}_{F}-\underline{R}}+\frac{\widehat{R}_{F}}{\bar{R}-\widehat{R}_{F}} .
$$




\section{Appendix C: On Under-investment in the Risky Sector}

We are going to show the claims in Sect. 4.4 by the following proposition:

Proposition 8 There does not exist an equilibrium with 0 -deposit insurance and $y_{F}>$ $\widehat{y}_{F}$.

Proof The proof is an immediate consequence of the following two assertions (A) and (B):

(A) There does not exist an equilibrium with 0 -deposit insurance, $y_{F}>\widehat{y}_{F}$ and no default.

(B) There does not exist an equilibrium with 0 -deposit insurance, $y_{F}>\widehat{y}_{F}$ and default.

Let us proceed under the assumption $\delta=0$.

Regarding (A), we observe that an equilibrium with 0-deposit insurance and no default is a Radner equilibrium with complete markets. Hence it is equivalent to an Arrow-Debreu equilibrium, by Proposition 19.D.1 of Mas-Colell et al. (1995). Therefore, the equilibrium allocation is efficient and satisfies $y_{F}=\widehat{y}_{F}$.

Regarding (B), let us use $y_{F}$ to parametrize (individually and socially) feasible consumption plans with equal treatment of households (like in (12) and (13)):

$$
\begin{aligned}
& c_{g}\left(y_{F}\right)=f\left(y_{F}\right)+\left(\omega-y_{F}\right) \bar{R} ; \\
& c_{b}\left(y_{F}\right)=f\left(y_{F}\right)+\left(\omega-y_{F}\right) \underline{R} .
\end{aligned}
$$

Then $\frac{d}{d y_{F}}\left(\frac{c_{g}}{c_{b}}\right)=\frac{1}{c_{b}^{2}} \cdot[\cdot]$ with

$$
\begin{aligned}
{[\cdot] } & =\left(f^{\prime}-\bar{R}\right) \cdot\left(f+\left(\omega-y_{F}\right) \underline{R}\right) \\
& -\left(f+\left(\omega-y_{F}\right) \bar{R}\right) \cdot\left(f^{\prime}-\underline{R}\right) \\
& =\left(f^{\prime} \cdot\left(\omega-y_{F}\right)+f\right) \cdot(\underline{R}-\bar{R})<0 .
\end{aligned}
$$

That is, $c_{g} / c_{b}$ is decreasing in $y_{F}$. By Eq. (27) in Gersbach et al. (2015) (or the equilibrium condition (12) in this paper),

$$
\frac{c_{g}}{c_{b}}=\left[\frac{\sigma\left(\bar{R}_{E}-R_{F}\right)}{(1-\sigma)\left(R_{F}-\underline{R}_{E}\right)}\right]^{\frac{1}{\theta}}
$$

holds at equilibrium. In case $\underline{R}_{E}=0$,

$$
\frac{c_{g}}{c_{b}}=\left[\frac{\sigma\left(\bar{R}_{E}-R_{F}\right)}{(1-\sigma) R_{F}}\right]^{\frac{1}{\theta}} .
$$

Hence $\frac{\bar{R}_{E}}{R_{F}}$ is decreasing in $y_{F}$ as long as $\underline{R}_{E}=0$. 
According to Proposition 5 of Gersbach et al. (2015), there exists an equilibrium without default (and with 0-deposit insurance) where the bank is on the brink of defaulting in the bad state. Let $D^{o}$ denote the amount of deposits and $E^{o}$ denote the amount of equity in that equilibrium. Then the equilibrium returns are $\bar{R}_{E}^{o}=$ $\bar{R}+\frac{D^{o}}{E^{o}} \cdot\left(\bar{R}-\widehat{R}_{F}\right)$ and $\underline{R}_{E}^{o}=0$. In general,

$$
\bar{R}_{E}=\bar{R}+\frac{D}{E} \cdot\left(\bar{R}-R_{F}\right) .
$$

Now suppose that there exists an equilibrium with default and $y_{F}>\widehat{y}_{F}$. At such an equilibrium, $R_{F}<\widehat{R}_{F}$ and $\frac{\bar{R}_{E}}{R_{F}}<\frac{\bar{R}_{E}^{o}}{\widehat{R}_{F}}$. Consequently, $\bar{R}_{E}<\bar{R}_{E}^{o}$ or

$$
\bar{R}+\frac{D}{E}\left(\bar{R}-R_{F}\right)<\bar{R}+\frac{D^{o}}{E^{o}}\left(\bar{R}-\widehat{R}_{F}\right) .
$$

Since $R_{F}<\widehat{R}_{F}, D / E<D^{o} / E^{o}$ has to hold. But then

$$
\frac{D}{E}\left(\underline{R}-R_{F}\right)>\frac{D^{o}}{E^{o}}\left(\underline{R}-\widehat{R}_{F}\right) \text {. }
$$

For either $\frac{D}{E}\left(\underline{R}-R_{F}\right) \geq 0>\frac{D^{o}}{E^{o}}\left(\underline{R}-\widehat{R}_{F}\right)$ or $0>\frac{D}{E}\left(\underline{R}-R_{F}\right)>\frac{D}{E}\left(\underline{R}-\widehat{R}_{F}\right)>$ $\frac{D^{o}}{E^{o}}\left(\underline{R}-\widehat{R}_{F}\right)$,

$\frac{D}{E}\left(\underline{R}-R_{F}\right)>\frac{D^{o}}{E^{o}}\left(\underline{R}-\widehat{R}_{F}\right)$ implies $\underline{R}_{E}>\underline{R}_{E}^{o}=0$. Thus assuming an equilibrium with default and $y_{F}>\widehat{y}_{F}$ leads to the conclusion that there is no default at that equilibrium, a contradiction. This shows the assertion.

\section{References}

Acharya, V.V., Santos, J.A.C., Yorulmazer, T.: Systemic risk and deposit insurance premiums. FRBNY Econ Policy Rev 16, 89-99 (2010)

Allen, F., Carletti, E., Marquez, R.: Deposits and bank capital structure. J Financ Econ 118, 601-619 (2015)

Allen, F., Gale, D.: Financial contagion. J Polit Econ 108(1), 1-33 (2000)

Allen, L., Saunders, A.: Forbearance and valuation of deposit insurance as a callable put. J Bank Finance 17(4), 629-643 (1993)

Bolton, P., Freixas, X.: Equity, bonds, and bank debt: capital structure and financial market equilibrium under asymmetric information. J Polit Econ 108(2), 324-351 (2000)

Boyd, J.H., Chang, C., Smith, B.D.: Deposit insurance: a reconsideration. J Monet Econ 49(6), 1235-1260 (2002)

Boyd, J.H., Chang, C., Smith, B.D.: Deposit insurance and bank regulation in a monetary economy: a general equilibrium exposition. Econ Theor 24, 741-767 (2004)

Calomiris, C. W., Jaremski, M.: Deposit insurance: theories and facts. NBER Working Paper Series, Working Paper No. 22223 (2016)

Chan, Y., Greenbaum, S.I., Thakor, A.V.: Is fairly priced deposit insurance possible? J Finance 47(1), 227-245 (1992)

Diamond, D.W.: Financial intermediation and delegated monitoring. Rev Econ Stud 51(3), 393-414 (1984)

Dreyfus, J.-F., Saunders, A., Allen, L.: Deposit insurance and regulatory forbearance: are caps on insured deposits optimal? J Money Credit Bank 26(3), 412-438 (1994)

Flannery, M.J.: Pricing deposit insurance when the insurer measures bank risk with error. J Bank Finance 15(4-5), 975-998 (1991)

Freixas, X., Rochet, J.-C.: Fair pricing of deposit insurance. Is it possible? No. Res Econ 52(3), 217-232 (1998)

Freixas, X., Rochet, J.-C.: Microeconomics of Banking, 2 edn. Cambridge: MIT Press (2008)

Gersbach, H., Haller, H., Müller, J.: The macroeconomics of Modigliani-Miller. J Econ Theory 157, 10811113 (2015) 
Holmström, B., Tirole, J.: Financial intermediation, loanable funds, and the real sector. Quart J Econ 112, 663-691 (1997)

Kahn, C.M., Santos, A.C.: Liquidity, Payment, and Endogenous Financial Fragility. Unpublished Paper, Federal Reserve Bank of New York (2005)

Jerman, U., Quadrini, V.: Macroeconomic effects of financial shocks. Am Econ Rev 102(1), 238-71 (2012)

Lucas, D.: Measuring the cost of bailouts. Annu Rev Econ 11, 85-108 (2019)

Madan, D., Unal, H.: Pricing reinsurance contracts on FDIC losses. Financ Mark Inst Instrum 17(3), 225247 (2008)

Marcus, A.J., Shaked, I.: The valuation of FDIC deposit insurance using option-pricing estimates. J Money Credit Bank 16(4), 446-460 (1984)

Mas-Colell, A., Whinston, M.D., Green, J.R.: Microeconomic Theory. Oxford: Oxford University Press (2015)

McCulloch, J.H.: Interest-risk sensitive deposit insurance premia: stable ACH estimates. J Bank Finance 9(1), 137-156 (1985)

Merton, R.C.: An analytical derivation of the cost of deposit insurance and loan guarantees: an application of modern option pricing theory. J Bank Finance 1(1), 3-11 (1977)

Merton, R.C.: On the cost of deposit insurance when there are surveillance costs. J Bus 51(3), 439-452 (1978)

Pennacchi, G.G.: Deposit insurance, banking regulation, and financial system risks. J Monetary Economics, 53(1), 1-30 (2006)

Pennacchi, G.G.: Deposit insurance. Paper prepared for AEI Conference on Private Markets and Public Insurance Programs. March (2009)

Plaut, S. E.: Reinsurance and Securitization of Deposit Insurance; A Workable Proposal for Risk-Based Pricing. Research Program in Finance Working Papers, No. RPF-207, University of California at Berkeley (1991)

Ronn, E.I., Verma, A.K.: Pricing risk-adjusted deposit insurance: an option-based model. J Finance 41(4), 871-895 (1986)

Sheehan, K.P.: Catastrophe securities and the market sharing of deposit insurance risk. FDIC Bank Rev 1997, 1-16 (2003)

Vives, X.: Competition and Stability in Banking: The Role of Regulation and Competition Policy. Princeton: Princeton University Press (2016)

Zame, W.R.: Efficiency and the role of default when security markets are incomplete. Am Econ Rev 83, $1142-1164(1993)$

Publisher's Note Springer Nature remains neutral with regard to jurisdictional claims in published maps and institutional affiliations. 